\title{
Multiscale Strategic Planning Model for the Design of Integrated Ethanol and Gasoline Supply Chain
}

\author{
Andersen F. ${ }^{1,2}$, Díaz M.S. ${ }^{1}$, Grossmann I.E. ${ }^{2 *}$ \\ ${ }^{1}$ Planta Piloto de Ingeniería Química, PLAPIQUI, Universidad Nacional del Sur, \\ CONICET. Camino La Carrindanga km 7, 8000 Bahía Blanca, ARGENTINA \\ ${ }^{2}$ Department of Chemical Engineering, Carnegie Mellon University, Pittsburgh PA 15213, US
}

\begin{abstract}
In this paper, we address the design and planning of an integrated ethanol and gasoline supply chain. We assume that the supply chain is composed of harvesting sites, production sites for ethanol, petroleum refineries, distribution centers where blending takes place, and the retail gas stations where different blends of gasoline and ethanol are sold. We postulate a superstructure that combines all the components of the supply chain. We consider different means of transportation that connect the nodes in the superstructure. We model this multiscale design of integrated ethanol and gasoline supply chain as a multiperiod MILP model for given forecasts of demand for different blends over the entire time horizon. In order to identify the regions of the US where investments are needed and the optimal configuration of the network, we first consider a strategic planning model in which gasoline stations are aggregated in the different regions. We then consider a second detailed formulation where regions are disaggregated into gas stations in order to also determine the retrofit projects for the selection of blending pumps over their expected life. A bilevel decomposition algorithm is proposed to solve the detailed model. We illustrate the application of these MILP models with two large-scale problems..
\end{abstract}

\section{Keywords}

Supply Chain, Gasoline and Ethanol, Gas Stations Planning, Bilevel decomposition

*Corresponding author: grossmann@cmu.edu 


\section{Introduction}

During the last decade the increasing concern on limited fossil fuels and environmental issues has brought attention to ethanol as a major energy source from biomass. Ethanol can help to address the need for new liquid fuels as complement of fossil fuels for the next decades. Furthermore, ethanol is the most promising liquid fuel that stands for the commitment of the RFS (Renewable Fuel Standard), part of the Energy Independence and Security Act of 2007 from the US, where the goal is to accomplish the production of 16 billion gallons of cellulosic biofuels by 2022 (Energy Independence and Security Act of 2007; National Biofuels Action Plan, USDA, DOE, 2008). The feasibility of introducing ethanol in fuel markets has already been proved. Currently, blends of gasoline and ethanol can be used by more than $80 \%$ of the current light-duty transportation vehicles (Datta et al., 2011).Some ethanol production technologies have already been developed and are being improved with the purpose of making ethanol more competitive as compared to gasoline, and releasing the dependence on governmental subsidies. Along this line, Martín and Grossmann (2012) have optimized production processes taking into account the use of raw materials, water and energy for first, second and third generation of biofuels. Vimmerstedt et al. (2012)haveused a systems dynamics approach to provide a framework to execute subsidies policy, focusing on the downstream supply chain.Theseauthors conclude that subsidies are required for the distribution and dispensing infrastructure to introduce high-blend ethanol into fuel markets. Akgul et al. (2012) haveanalyzed a hybrid first/second generation biofuel supply chain, taking into account trade-offs between economic and environmental objectives.

However, there are other challenges that have not yet been solved. Main concerns are related to the downstream supply chain, where petroleum and ethanol industries must be coordinated when blending their products. Other issues of concern are related to biomass transportation, supply chain design of bioethanol and its integration to gasoline supply chain. Wakeley et al. (2009) evaluate the transportation effects for the production of E85 (a blend of 85\% ethanol and 15\% gasoline) by a combination of corn and cellulosic ethanol and recommends regional concentration of E85 blends to reduce costs. In the areas where feedstock sources are not easily available, these authorsrecommend to explore other fuel alternatives. Ethanol transportation by truck is especially useful to reduce storage requirements at biorefineries because it offers more flexibility to accommodate to uncertain market demands (US Department of Agriculture). Eksioglu et al. (2009) analyze logistical challenges on the biomass distribution and supply. Theyconclude that when biomass availability is low and transport costs are high, smaller size biorefineries become economical. The integration of ethanol and gasoline has been studiedby Russell et al.(2009) who focusonthe logistics management process, railway transportation and intermediate storage. These authors propose the inclusion of intermediate hub storage to better complement railway transportation, the building of strategic relationships among petroleum distribution centers, ethanol producers and transportation providers. Furthermore,recent reports of NREL, DOE and USDA analyze the impact of blending ethanol and gasoline. To address some of the issues investigated, Russell et al. (2009) propose the use of intermediate hub storage to better complement railway transportation,the building of strategic relationships among petroleum distribution centers, ethanol producers and transportation providers.

Supply chain problems are often modeled as mixed integer linear problems (MILP), which canbecome intractable due to their size (Grossmann, 2012). To overcome this issue, decomposition strategies are applied, such as Lagrangean decomposition, Benders decomposition and Bilevel decomposition. Iyer and Grossmann (1998) address the Long-Range

Planning with a Bilevel Decomposition Algorithm where the higher level problem determines the processes that should be selected and the capacity and production planning are determined at the lower level problem. Since the former provides an 
upper bound for the profit and the latter a lower bound, these sub problems are solved iteratively by adding cuts until the bounds are within a given tolerance.

In this work, we propose MILP models for the design of the integrated supply chain of ethanol and gasolineand we apply a Bilevel Decomposition algorithm to reduce the computational expense.This paper is organized as follows. Section 2 provides the background to gasoline and bioethanol supply chains. The problem statement ispresented in Section 3 . The MILP formulation is given in Section 4 where constraints for harvesting sites,ethanol plants,distribution centers, retail centers and objective function are described. In Section 5 two examples are presented for the aggregate and detailed models. Finally, the decomposition algorithm and results for the detailed model are discussed in the supplementary material.

\section{Background}

The petroleum supply chain is often divided into two major components: upstream and downstream.It can further be classified into different stages such asexploration and extraction itself, petroleum refining and retail consumption. These stages are illustrated in Fig. 1.

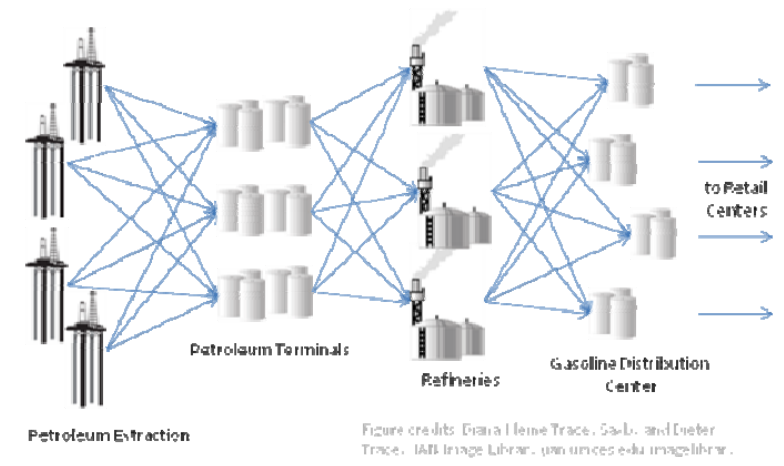

Fig 1. Petroleum Supply Chain

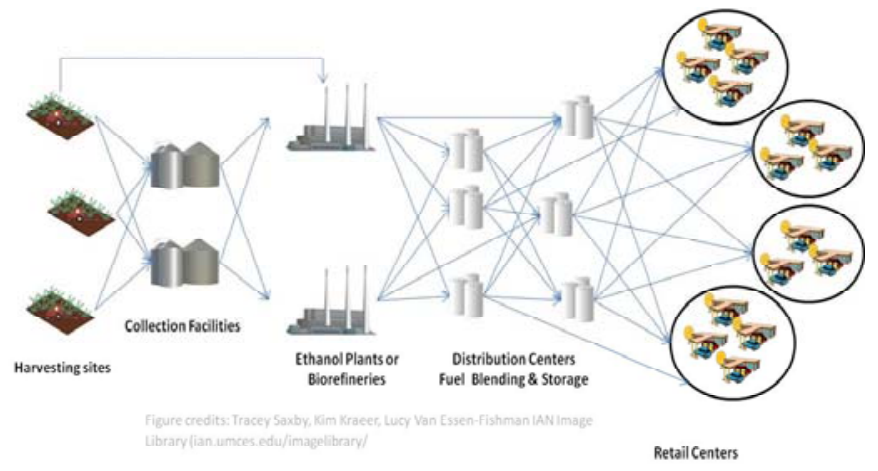

Fig. 2 Ethanol Supply Chain

The different echelons of the supply chain are connected to each other mainly by pipelines. The petroleum extracted at the very beginning of the chain is transported to crude oil terminals. These terminals supply refineries with crude oil, where it is transformed into an assorted set of products. The one of interest in this paper is gasoline, which is transported to distribution centers and then sent to retail centers. The petroleum pipeline network is well developed within the US andmost transportation in the petroleum supply chain takes place by pipeline (Neiro and Pinto, 2004).

A general scheme of the bioethanol supply chain is illustrated in Fig. 2, where the raw material (either first, second or third generation) is harvested and sent to collection facilities or ethanol plants. Collection facilities feed the ethanol plants with biomass (You and Grossmann, 2008). Once ethanol is produced, it is sent to distribution centers for storage andblending with gasoline. Finally, distribution centers send ethanol blends to retail centers (gas stations). Transportation in the ethanol supply chain is mainly carried out by trucks, even though there is the possibility to use railways, even from the collection facilities (You and Wang, 2011).

The multiple warehouses at distribution centers level are placed so as to take advantage of railway transportation. Therefore, in many cases intermediate warehouses are needed depending on the existence of railway facilities in ethanol plants and in retail centers (Rusell et al., 2009). 
The ethanol supply chain must be coordinated with the gasoline supply chain in order to manage a lower cost ethanol blend. The integration of these two supply chains is addressed to carry out a cost-effective coordination. Since the main focus of the modelis on the downstream of the supply chain, upstream details such as selection of collection facilities have been simplified. Figure3 shows the integrated ethanol-gasoline supply chain considered in this paper.

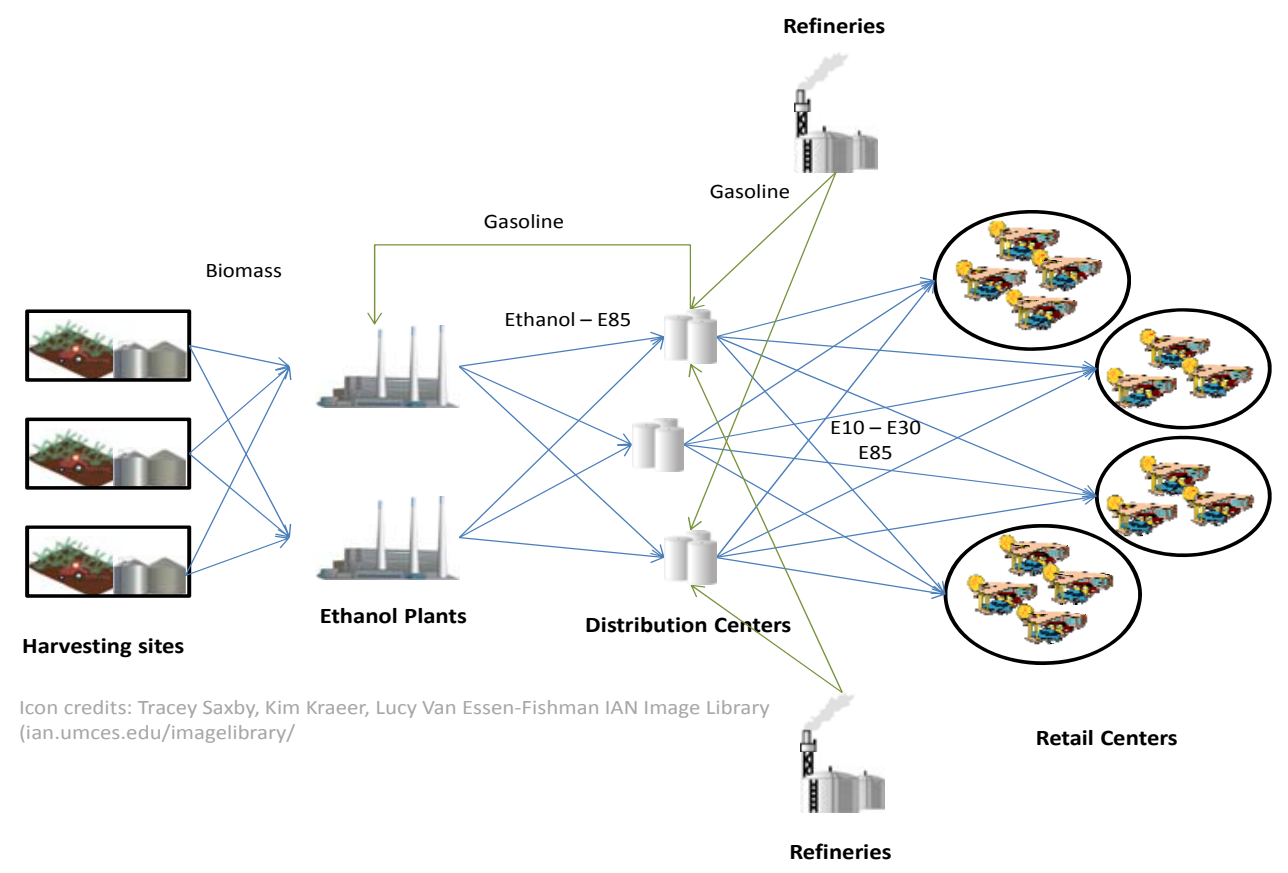

Fig. 3. Superstructure of Gasoline and Ethanol Supply Chain

Within the harvesting sites,storage is required for the biomass. After this stage, the biomass is sent to the ethanol plants (or biorefineries) where bioethanol is produced through any of the technologies considered: biochemical, thermochemical or a hybrid technology between these two (Martín and Grossmann, 2012). Ethanol is transported to the distribution centers, which in turn receive gasoline from the refineries. The distribution centers feed the retail centers with the fuel blends required by the market, mixing or not E85 and gasoline. Our model considers that the lowest ethanol blend at retail centers should be E10, which is currently the gasoline that is sold in most of the US gas stations.Retail centers represent a group of gas stations, where every fuel blend can be fed and stored in underground tanks.Some gas stations sell only the fuel blends they receive while others can blend the fuels stored in their underground tanks to producealternative blends using blending pumps operated by theconsumers. Blender pumps allow the consumer to select between several ethanol blends, according to the brands preprinted in the fuel pump. Figure4 shows how the blender pumps work for the case when E10 and E85 are stored in the tanks with the possibility of producing the E30 blend.

The advantage of blender pumps is that they allow having a set of several blends available to consumers. While their fixed capital investment is higher than the required for a normal gas station, it is much lower than the investment requiredto have each blend available separately with different tanks and facilities. 


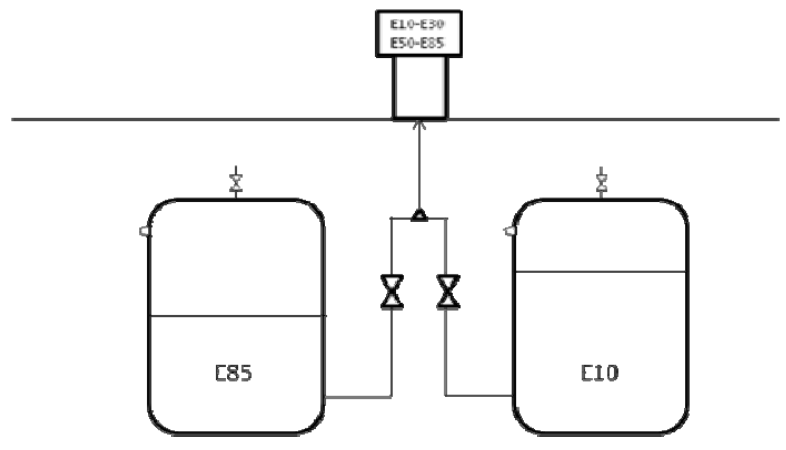

Fig. 4. Blender Pump Scheme

One of the main issues aboutselling several fuel blends in the market in the short term is to estimate the demand for each blend. This not only depends on the flexibility of the car fleet, but also on the driver's preference and activities, and on how the car performs with each blend in different types of trips (eg. flat vs mountain), and also on the relation between price and mileage for each vehicle. Given this situation, it is preferable to have a blending pump in a gas station because it allows the sale of several blends regardless of the product stored in the underground tanks.

Summarizing some of the issues discussed in this section, the present work addresses the optimal design of an integrated ethanol and gasoline supply chain (Fig. 3) that accounts for details in downstream operations and general characteristics of the upstream operations. A set of harvesting sites to produce the raw materials needed to obtain cellulosic ethanol and a set of ethanol plants with different production technologies are considered. Also a set of distribution centers for gasoline and E85, or both products together, a set of refineries and a set of retail centers are considered. Mixing of fuels can occur within distribution centers or within retail centers, which are defined by a set of gas stations. Transport from refineries to distribution centers is only considered with pipelines. Railway and truck transportation is considered between ethanol plants and distribution centers. For simplicity, blends considered in this model are: E10 (currently used in U.S.), E30 and E85. However, the model can be easily extended to consider additional blends. Also, for simplicity we consider that the different grades of gasoline are aggregated into a single grade, although once again the model can easily accommodate multiple grades of gasoline.

\section{Problem Statement}

The problem addressed in this paperis based on the integrated superstructure of ethanol and gasoline supply chain shown in Fig. 3 and is stated as follows. Two different types of biomass are considered: wood residues and switchgrass. After harvesting, drying and intermediate storage are required. We assumethat these operations occur within the same location of the harvesting site.Biomass transportation to biorefineries, which is a significant bottleneck of the supply chain due to the biomass low density, is carried out mainly by truck.Biorefineries produce ethanoland E85, which is composed of $85 \%$ ethanol and $15 \%$ gasoline. A percentage of the ethanol produced is consumed by other industries, and E85 blend is sent to gasoline distribution centers. Gasoline is produced at the refineries and sent to the gasoline distribution centers, which in turn can feed ethanol plants as it is shown in Fig 3. The E85 blend from the ethanol plants and gasoline from the oil refineries are transported to the gasoline distribution centers to produce different blends (E10 or E30) in order to supply them to retail centers. Blending of ethanol and gasoline can occur at the distribution centers or in the retail center itself. Sales of E10, E30 and E85take place at the retail center. We consider a time horizon of several years during which 
demands are specified for E10, E30 and E85. The total demand of fuel is estimated from the average fuel consumption published on 2002 Economic Census. For each blend we assume that the demand is given by a percentage of this total demand.

We formulate two models of different levels of detail. The first oneis an aggregated model that considers the fuel demand per region without details of the gas stations. In contrast, the second model considers the number of gas stations per region. Since the only difference between the two models is at the retail centers, the description of the other stages in the supply chain (harvesting sites, ethanol plants and distribution centers) is the same for bothmodels. Existing and potential capacity for the ethanol plants, refineries and distribution centers are given. Different means of transportation are available for each product (truck, railway and/or pipeline)

At each stage of the supply chain the following information is assumed to be given.

- For each harvesting siteand both sources of biomasswe are given the capacity of dry feedstock production. We consider harvesting fields and storage facilities in the same node of the supply chain becausethe paper focuses on thedownstream of the supply chain (retail centers and gas stations).

- For each potential ethanol plant in both modelswe consider three available technologies: biochemical, thermochemical and hybrid (gasification + fermentation) with three different levels of investment, taking advantage of the economy of scale: small, medium and large. For each one,we are givenexisting capacity andyields.

- For each potential distribution center in both models,we also consider three different levels for the investment. Also blending of E85 and gasoline can take place to produce E30 and E10 blends.

- Finally, for each retail center in the aggregated model, we consider the fuel demandof every blend (E10, E30 and E85), frequency of replenishment, initial capacity and investment cost.

- For each retail center in the detailed model, we consider the possibility of installing blending pumps through retrofits. Retrofits on each gas station are mandatory every ten (10) years, and in between they are optional.Additional data are: fuel demand of every blend (E10, E30 and E85), frequency of replenishment, initial capacity,number of existing gas stations, average capacity of underground storage in gas stations, investment cost for new gas stations, investment cost for retrofits on gas stations and thetime required to carry out a retrofit or build a new gas station.

Given the above information the following decisions must be made to design an optimal integrated supply chain:

$\checkmark$ In Harvesting Sites (HS)

- Location and production capacity

- Which HS feeds each Ethanol Plant

$\checkmark$ In Ethanol Plants (EP)

- Location

- Technology of each EP installed and production capacity

- Amount of ethanolproduced between 50\% and $100 \%$ of installed capacity

- Interconnectionbetween EP and gasoline distribution centers

$\checkmark$ In Gasoline Distribution Centers (DC)

- Location and storage capacity 
- Level of Production of blends between $50 \%$ and $100 \%$ of installed capacity

- Which Refinery feeds each DC

- Which DC deliversgasoline for each EP

- If E10 and E85 are mixed to produce blends (E30), or supply these products to Retail Centers

$\checkmark$ In Retail Centers (RC) for aggregated model

- Sales of fuel blends to satisfy the total demand

$\checkmark$ In Retail Centers (RC) for detailed model

- Number and type of Gas Stations (GS) in each RC

- Operating GS to meet the demand in each time period

- Schedule of retrofits over each GSand new GS needed

- Sales of fuel blends to satisfy the total demand

In order to select these decisions two multiperiod MILP models are proposed (aggregated and detailed)to minimize the total cost of the supply chain, which includes terms for capital cost, production cost, transportation cost, storage cost, distribution cost, and purchase cost of biomass and gasoline. To calculate these costs we have considered linear cost models with fixed charges.

The major assumptions in the proposed models include the following. The inventory level of product $p$ is calculated through a specified number of replenishments per time period (Eq. (9) for ethanol plants). The amount stored of product $p$ is bounded between one and three times the inventory level (Eq. (10) and (11) for ethanol plants) (Guillén-Gosálbez and Grossmann, 2009). The turnover ratio considered is 2 weeks for ethanol products, 3 months for biomass, and 10 days for fuel blends in gas stations.

The final market of fuel blends is composed of gas stations. However, if we considered one retail center per gas station in the supply chain, the size of the problem would be very large. Therefore, in the detailed model, we let retail centers represent an entire county in which the gas stations are included. It is only necessary to keep track of the number of gas stations to somehow determine the capacity of the retail centers. We assume different types of gas stations classified by the products they can sell. This information is displayed inthe first two columns of Table 1.There aregas stations that can only provide a unique blend (single product gas stations: G1for E10 and G2 for E30), and those that can provide the customers with a set of blends (multiproduct gas stations, G3 for E10, E30 and E85) through the installation of blending pumps.

Every fuel blend in multiproduct gas stations (G3) must be produced by mixing the existing fuel blends stored in the underground tanks (this kind of gas stations can also provide customers with the fuel stored without mixing it). The same applies to the distribution centers. The equations describing the mixing process of distribution centers introduce in principle non-linearities in the model. However a linear model can be derived by computing mass balance coefficients that represent fractions of the gasoline and ethanol, or of E10 and E85 to obtain the E30 blend (see Table 2) 
Table 1. Types of Gas Stations and Retrofits

\begin{tabular}{|c|c|c|c|c|}
\hline $\begin{array}{c}\text { Type of } \\
\text { Gas } \\
\text { Station }\end{array}$ & $\begin{array}{l}\text { Product } \\
\text { produced }\end{array}$ & $\begin{array}{l}\text { Type of } \\
\text { Retrofit }\end{array}$ & $\begin{array}{c}\text { Original } \\
\text { type of GS }\end{array}$ & $\begin{array}{c}\text { Final type } \\
\text { of GS }\end{array}$ \\
\hline \multirow{2}{*}{ G1 } & \multirow{2}{*}{ E10 } & V1 & G1 & G1 \\
\hline & & V2 & G1 & $\mathrm{G} 2$ \\
\hline \multirow{2}{*}{ G2 } & \multirow{2}{*}{ E30 } & V3 & G1 & G3 \\
\hline & & V4 & G2 & $\mathrm{G} 2$ \\
\hline \multirow{2}{*}{ G3 } & \multirow{2}{*}{ E10; E30; E85 } & V5 & G2 & G3 \\
\hline & & V6 & G3 & G3 \\
\hline
\end{tabular}

For investments for gas stations we assume that these could be new stations or retrofits of existing ones. We also assume that the gas stations have a specified lifetime after which they must undergo a change of tanks. At this point a gas station may keep supplying the same products (V1, V4 or V6), switch the products without large investments (V2) or else invest in additional tanks and blending pumps to produce additional products (V3 or V5). The different types of retrofits are listed in the last three columns of Table 1. Note that retrofits from G1 and G2 to G3 require installing blending pumps.

Furthermore, we consider the possibility to satisfy high ethanol blends demand with lower ethanol blends, as flex-fuel cars requiring E85 can also work with lower ethanol blends. However, a minimal quantity of each blend demand that has to be fulfilled with that blend.

\section{MILP formulation}

In this section we describe the multiperiod MILP models (aggregated and detailed)to optimize investments in the ethanol and gasoline supply chain.

\subsection{Harvesting Sites}

The mass balance of the harvesting sites is included in Eq. (1) and establishes that the amount of feedstock $b$ produced in harvesting site $i$ in time period $t\left(b h s_{b i t}\right)$ must be equal to the biomass sent to the ethanol plants $j$ by transportation mode $m\left(q b_{b i j m t}^{I J}\right)$.

bhs $_{\text {bit }}=\sum_{j} \sum_{m} q b_{\text {bijmt }}^{I J} \quad \forall b, i, t$

Eq. (2) states that if in the harvesting site $i$ the feedstock $b$ is produced $\left(y_{b i t}^{I}=1\right)$, then the amount produced $\left(b h s_{b i t}\right)$ should be less or equal to the total available quantity $\left(A B_{b i t}\right)$. This total amount is related to the level of production. 
There is also an upper bound on the amount of transported biomass $b$ by transportation modem from harvesting site $i$ in time period $t$. This upper boundtakes into account a maximum number of units in transportation mode $m$ (trucks or freight car) and theircorresponding weight capacity.

\subsection{Ethanol Plants}

The inventory balance for biomass in ethanol plants in Eq. (3) establishesthat allfeedstock $b$ coming into ethanol plant $j$ in period time $t\left(q b_{b i j m t}^{I J}\right)$ plus the amount stored at the end of the previous time period $\left(s b_{b j t-1}^{J}\right)$, should be equal to the amount of feedstock $b$ used as raw material in ethanol plant $j$ in period time $t\left(w_{b j q t}^{I-B}\right)$ plus the amount that remains stored at the end of time period $t\left(s b_{b j t}^{J}\right)$.

$$
\sum_{i} \sum_{m} q b_{b i j m t}^{I J}+s b_{b j t-1}^{J}=\sum_{q} w_{b j q t}^{I-B}+s b_{b j t}^{J} \quad \forall b, j, t
$$

The mass balances in ethanol plants establish the relationship between the inlet and outlet flows. In Eq. (4), $\mu^{P}{ }_{b q}$ denotes the amount of biomass brequired to produce ethanol with production technology $q$, and the mass balance

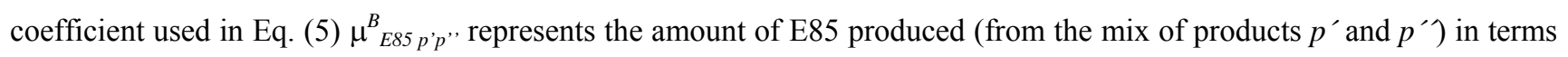
of the amount of product $p^{\prime}$ consumed; $w_{j p q t}^{I-J}$ represents the amount of gasoline used to produce ethanol in plant $j$ with production technology $q$ in time period $t$.

$$
\begin{aligned}
& w_{j, E 85, q t}^{O-J}=\sum_{b} \mu_{b q}^{P} w_{b j q t}^{I-B} \quad \forall j, q, t \\
& w_{j p q t}^{O-J}=\mu_{p, p^{\prime}=G A S, p^{\prime \prime}=E 100}^{B} w_{j, p^{\prime}=G A S, q t}^{I-J} \quad \forall j, p=E 85, q, t
\end{aligned}
$$

In a similar way, the mass balance for gasoline is obtained through Eq. (6). The only difference is that we do not include storage terms; $q p^{J K}{ }_{j k m p t}$ represents the amount of gasoline transported from distribution center $k$ to ethanol plant $j$ by transportation mode $m$ in time period $t$.

$$
\sum_{k} \sum_{m} q p_{j k m p t}^{J K}=\sum_{q} w_{j p q t}^{I-J} \quad \forall j, p=G A S, t
$$


The inventory balance for the product (E85) is represented in Eq. (7), where the amount of E85 produced in plant $j$ with production technology $q$ in time period $t\left(w_{j p q t}^{O-J}\right)$ plus the amount stored at the end of the previous time period must be equal to the amount transported from ethanol plant jto distribution center $k$, and other markets of ethanol consumption fby transportation mode min time period $t\left(q p^{J K}{ }_{j k m p t}\right.$ and $q p^{J F}$ fjmpt respectively), plus the amount that remains stored at the end of time period t.Eq. (8) shows thepercentage of ethanol $\left(\beta_{\mathrm{j}}\right)$ devoted to the consumption of other industries.

$$
\begin{aligned}
& \sum_{q} w_{j p q t}^{O-J}+s p_{j p t-1}^{J}=\sum_{k} \sum_{m} q p_{j k m p t}^{J K}+\sum_{k} \sum_{m} q p_{f j m p t}^{J F}+s p_{j p t}^{J} \quad \forall j, p=E 85, t \\
& \sum_{f} \sum_{m} q p_{f j m p t}^{J F}=\beta_{j} w_{j p q t}^{O-J} \quad \forall j, p=E 85, t
\end{aligned}
$$

As it was stated in the previous section, we assume that the inventory level of product $p$ ( $i l^{E P}{ }_{j p t}$ ) is the minimum amount between replenishments required to provide markets with product $p$. It is defined in Eq. (9) as the ratio of the production flows of ethanol plants to the turnover ratio required for each ethanol plant $j$ in each time period $t, T O R_{j t}^{J}$. This parameter indicates the number of times that the stock will be entirely replaced per time period (number of replenishments per time period). Eqs. (10) and (11) provide lower and upper bounds on the stored amount, based on the inventory level and based on the factors $\lambda_{\text {MAX }}$ and $\lambda_{\text {MIN }}$.

$i l_{j p t}^{E P}=\frac{\sum_{m}\left(\sum_{k} q p_{j k m p t}^{J K}+\sum_{f} q p_{f j m p t}^{J F}\right)}{T O R_{j t}^{J}} \forall j, p=E t h, t$

$s p_{j p t}^{J} \leq \lambda_{M A X} i l_{j p t}^{E P} \quad \forall j, p, t$

$s p_{j p t}^{J} \geq \lambda_{M I N} i l_{j p t}^{E P} \quad \forall j, p, t$

The binary variable $y_{j q s t}^{J}$ represents whether or not the investment takes place for ethanol plant $j$ with production technology $q$ and size levels within time period $t$. Eqs. (12) and (13) set lower and upper bounds on the capacity of the new plants, represented by the variable $n p c^{J}{ }_{j q s}$.

$P C_{j q s-1}^{E P} y_{j q s t}^{J} \leq n p c_{j q s t}^{J} \leq P C_{j q s}^{E P} y_{j q s t}^{J} \quad \forall j, q, s>1, t$

$L B P C_{j q}^{E P} y_{j q s t}^{J} \leq n p c_{j q s t}^{J} \leq P C_{j q s}^{E P} y_{j q s t}^{J} \quad \forall j, q, s=1, t$ 
The production of ethanol plants is limited by the existing capacity $E P C_{j q}^{J}$, plus the capacity of the new plants built from period 1 to period $t$ (Eqs. 14 and15). A scalar between 0 and $1\left(\theta_{j q}^{J}\right)$ is used to denote the minimum percentage of production that is allowed in each plant $j$ with production technology $q$.

$$
\begin{aligned}
& w_{j p q t}^{O-J} \geq \theta_{j q}^{J}\left(E P C_{j q}^{J}+\sum_{t^{\prime} \leq t} n p c_{j q s t^{\prime}}^{J}\right) \quad \forall j, p=E t h, q, t \\
& w_{j p q t}^{O-J} \leq E P C_{j q}^{J}+\sum_{t^{\prime} \leq t} n p c_{j q s t^{\prime}}^{J} \quad \forall j, p=E t h, q, t
\end{aligned}
$$

Due to the limit on the availability of capital investment, an upper bound on the total number of new ethanol plants per year $\mathrm{t}$ and per potential region $\mathrm{j}$ is imposed in Eq. (16) taking into account all the technologies.A practical limit is the number of new ethanol plants depending on their production technology; i.e., the biochemical or thermochemical technologies have a largerupper bound than the hybrid one because the former are at a more advanced stage than the hybrid plants. This aspect is addressed in Eq. (17).

$$
\begin{aligned}
& \sum_{q} \sum_{s} y_{j q s t}^{J} \leq N J_{j t}^{T O T} \quad \forall j, t \\
& \sum_{j} y_{j q s t}^{J} \leq N J_{q s t} \quad \forall q, s, t
\end{aligned}
$$

\subsection{Gasoline Distribution Centers}

The equations involved in this section are similar to those representing ethanol plants.

Eq. (18) is the inventory balance for gasoline, where the amount shipped from every refinery $l$ by transportation mode $m$ to distribution center $k$ in time period $t\left(q g_{k l m p t}^{L K}\right)$,plus the amount of gasoline stored in distribution center $k$ at the end of the previous time period, should be equal to the amount of gasoline that remains stored at the end of the time period $t$ plus the gasoline sent to every ethanol plant $j$ by transportation mode $m$ in period $t\left(q p_{j k m p t}^{J K}\right)$,plus the amount of gasoline mixed with every product $p^{\prime \prime}$ to produce product $p^{\prime}$ in period $t\left(w_{k p^{\prime} p p^{\prime \prime} t}^{I-K}\right)$.

$\sum_{m} \sum_{l} q g_{k l m p t}^{L K}+s p_{k p t-1}^{K}=\sum_{q} \sum_{p^{\prime} p^{\prime \prime}} \sum_{k p^{\prime} p p^{\prime \prime} t}^{I-K}+\sum_{j} \sum_{m} q p_{j k m p t}^{J K}+s p_{k p t}^{K} \quad \forall k, p=G A S, t$

In the same way, the amount of E85 delivered from every ethanol plant $j$ to distribution center $k$ by transportation mode $m$ in period $t\left(q p_{j k m p t}^{J K}\right)$ plus the amount of E85 stored in distribution center $k$ at the end of the previous time period( 
$\left.s p_{k p t-1}^{K}\right)$ must be equal to the quantity of E85 mixed with each product $p^{\prime \prime}$ to produce any product $p^{\prime}\left(w_{k p^{\prime}}^{I-K} p^{\prime \prime} t\right)$ plus the amount of E85 that remains stored in distribution center $k$ at the end of the time period $t\left(s p_{k p t}^{K}\right)(E q .19)$.

$$
\sum_{j} \sum_{m} q p_{j k m p t}^{J K}+s p_{k p t-1}^{K}=\sum_{q} \sum_{p^{\prime}} \sum_{p^{\prime \prime}} w_{k p^{\prime} p p^{\prime \prime} t}^{I-K}+s p_{k p t}^{K} \quad \forall k, p=E 85, t
$$

The mass balance for products (Eq.20), states that the amount of each product pproduced in distribution center $k$ in time period $t\left(w_{k p t}^{O-K}\right)$ should be equal to the amount of product $p$ delivered from distribution center $k$ to all retail centers $d$ by any transportation mode $m$ in this time period $t\left(q p_{d k m p t}^{K D}\right)$.

$$
w_{k p t}^{O-K}=\sum_{d} \sum_{m} q p_{d k m p t}^{K D} \quad \forall k, p, t
$$

All fuel blends are obtainedby mixing different amounts of gasoline and E85 according to the amount of ethanol required for the final blend. The mass balance coefficientfor different products can be calculated based on densities of gasoline and E85 and the amount used of each blend. Therefore, the mass balance coefficient $\mu_{p p^{\prime} p^{\prime \prime}}^{B}$, relates the input of $p^{\prime}$ with the output of $p$, mixing $p^{\prime}$ and $p^{\prime \prime}$, as shown in Eq. (21) (see Table 2).

$w_{k p t}^{O-K}=\sum_{p^{\prime} p^{\prime \prime}} \sum_{p p^{\prime} p^{\prime \prime}}^{B} w_{k p p^{\prime} p^{\prime \prime} t}^{I-K} \quad \forall k, p, t$

The definition of the inventory level in distribution centers is analogous to the definition of the inventory level in ethanol plants. The inventory level of product $p$ that should be kept in each distribution center $k$ in time period $t\left(i l^{D C}{ }_{k p t}\right)$,is calculated with Eq. (22) with the turnover ratio of this distribution center $k$ in time period $t$ (TOR ${ }_{k t}^{K}$ ), and the inlet flow of product $\mathrm{p}$ that is needed to produce every product $\mathrm{p}^{\prime}$ in a mixture with any product $\mathrm{p}^{\prime \prime}$ in distribution center $\mathrm{k}$ and time period $t\left(w_{p, p p " t}^{I-K}\right)$

$i l_{k p t}^{D C}=\frac{\sum \sum_{p^{\prime} p^{\prime \prime}} w_{k p^{\prime} p p^{\prime \prime} t}^{I-K}}{T O R_{k t}^{K}} \quad \forall k, p, t$

The amount of product $p$ stored in distribution center $k$ in time period $t$ is bounded by the average inventory level that is required to keep the necessary production. $\lambda_{\text {MAX }}$ and $\lambda_{\text {MIN }}$ are factorsrelated to the desired reliability of the storage.

$$
\begin{aligned}
& s p_{k p t}^{K} \leq \lambda_{M A X} \text { il }{ }_{k p t}^{D C} \quad \forall k, p, t \\
& s p_{k p t}^{K} \geq \lambda_{M I N} i l_{k p t}^{D C} \quad \forall k, p, t
\end{aligned}
$$


The binary variable $y_{k s t}^{K}$ represents whether a distribution center $k$ of size $s$ is installed or not in time period $t$. The new capacity $\left(n p c^{K}{ }_{k s t}\right)$ of distribution center kof size $s$ in time period $t\left(n p c^{K}{ }_{k s t}\right)$, is bounded between lower and upper bounds, according to Eqs. (25) and (26).

$$
\begin{aligned}
& P C_{k s-1}^{D C} y_{k s t}^{K} \leq n p c_{k s t}^{K} \leq P C_{k s}^{D C} y_{k s t}^{K} \quad \forall k, s>1, t \\
& L B P C_{k}^{D C} y_{k s t}^{K} \leq n p c_{k s t}^{K} \leq P C_{k s}^{D C} y_{k s t}^{K} \quad \forall k, s=1, t
\end{aligned}
$$

In Eq. (27) the production capacity of all products $p$ produced in distribution centerk within time period $t\left(w^{O-K}{ }_{k p t}\right)$ is limited bythe capacity of the initial set of distribution centers, plus the capacity of those distribution centers installed before the current time period.

$$
\sum_{p} w_{k p t}^{O-K} \leq E P C_{k}^{K}+\sum_{s} \sum_{t^{\prime} \leq t} n p c_{k s t^{\prime}}^{K} \quad \forall k, t
$$

Finally, Eq. (28) limits the total number of distribution centers that can be installed in time period $t$ and in potential location $k$ (taking into account all the sizes considered in the model), and Eq. (29) limits the number of distribution centers of size sthat can be installed in time period $t$.

$$
\begin{aligned}
& \sum_{s} y_{k s t}^{K} \leq N K_{k t}^{T O T} \quad \forall k, t \\
& \sum_{k} y_{k s t}^{K} \leq N K_{s t} \quad \forall s, t
\end{aligned}
$$

As indicated in the problem statement, we first consider an aggregated model without gas station details and then a detailed model with gas stations details. The difference is in the retail centers formulation. Equations (1) to (29) are included in both the aggregated and detailed models. In section 4.4 we describe the retail centers equations for the aggregated model, and in section 4.5 we discuss retail centers formulation for the detailed model.

\subsection{Retail Centers - Aggregated Model}

Due to multiple inlet and outlet products of the retail centers and the combination of these inputs to produce any product, non-linearities might arise in the mass balances. A disaggregation scheme is introduced to avoid these non-

linearities. Specifically, variables $w_{d p p^{\prime} p^{\prime \prime} t}^{I-D}$ are defined to represent the amount of product $p^{\prime}$ mixed with product $p^{\prime \prime}$ to produce product $p$ within retail center $d$ in time period $t$. The mass balance for inlet products on retail centers is expressed in Eq. (30). It states that every product $p$ that gets into a retail center $d$ in time period $t$ from any distribution center $k$ and by any transportation mode $m\left(q p_{d k m p t}^{K D}\right.$ ) plus the amount of product $p$ that remains stored in retail center $d$ since the end of the previous time period $\left(s p_{d p t-1}^{D}\right)$ must be equal to the consumption of product pto produce every product $p^{\prime \prime}$ with a mix of product $p^{\prime}$ in retail center $d$ in time period $t\left(w p_{d p^{\prime} p p^{\prime \prime} t}^{I-D}\right)$ plus the amount stored at the end of time period $t\left(s p_{d p t}^{D}\right)$. 


$$
\sum_{k} \sum_{m} q p_{d k m p t}^{K D}+s p_{d p t-1}^{D}=\sum_{p^{\prime} p^{\prime \prime}} w p_{d p^{\prime} p p^{\prime \prime} t}^{I-D}+s p_{d p t}^{D} \quad \forall d, p, t
$$

Eq. (31) states that the amount of product $p$ that is sold in retail center $d$ in time period $t\left(w p^{O-D}\right.$ dpt) must be equal to the sales.

$$
w p_{d p t}^{O-D}=\text { sales }_{d p t} \quad \forall d, p, t
$$

The relationship between inputs and outputs is given by the mass balance coefficient $\mu^{B}{ }_{p p^{\prime}} p^{\prime \prime}$ as it is shown in Eq. (32). This coefficientrelates the amount of product $p$ produced by mixing products $p^{\prime}$ and $p^{\prime \prime}$. Table 2 shows two examples: in the second line it can be noted that E30 can be obtained with $73.33 \%$ of E10 and 26.67\% of E85 (volume). The numerical value for the coefficient $\mu_{E 30, E 10, E 85}^{B}[\mathrm{~kg} \mathrm{E30} / \mathrm{kg} \mathrm{E10]}$ is obtained with the value of the density of each blend.

$$
w p_{d p t}^{O-D}=\sum_{p^{\prime} p^{\prime \prime}} \mu_{p p^{\prime} p^{\prime \prime}}^{B} w p_{d p p^{\prime} p^{\prime \prime} t}^{I-D} \quad \forall d, p, t
$$

Table 2. Mass balance coefficient for mixing fuel blends

\begin{tabular}{ccccc}
\hline & \multicolumn{4}{c}{ Raw materials } \\
& GAS & E10 & E85 & Eth \\
\hline E30 & 0.7 & - & - & 0.3 \\
E30 & - & 0.7333 & 0.2667 & - \\
\hline
\end{tabular}

Eqs. (33) to (35) represent constraints on blend sales as explained in Section 3. The demand of higher ethanol blends can be satisfied with lower ethanol blends. In these equations, parameter $D E M_{d t}$ refers to the demand of fuel (all ethanol and gasoline blends) in retail center $d$ in time period $t$, and the parameter $P B_{p}$ expresses what percentage of this demand corresponds to the demand of blend $p$ (Anderson, 2012).

Eq. (33) states that the summation of sales of every product $p^{\prime}$ that has a greater content of ethanol than blend $p$, should be less or equal than the summation of the demand of these fuel blends.Eq. (34) ensures that the sales of all fuel blends must be greater than these product demands. It is possible to relax this constraint because sales will increase to satisfy the demand, but a further increase would increase the objective function value, which is being minimized.Eq. (35) states that sales of E10 have to be greater or equal than E10 demand, because there is no other fuel blend that can satisfy its demand and also E10 can be used to satisfy the demand of other blends.

$$
\begin{aligned}
& \sum_{p^{\prime} \geq p} \text { sales }_{d p^{\prime} t} \leq \sum_{p^{\prime} \geq p} D_{d t} P M_{p^{\prime}} \quad \forall d, p>E 10, t \\
& \sum_{p} \text { sales }_{d p t} \geq \sum_{p} D E M_{d t} P B_{p} \quad \forall d, t \\
& \text { sales }_{d p t} \geq D E M_{d t} P B_{p} \quad \forall d, p=E 10, t
\end{aligned}
$$


We define the inventory level of product $p$ in retail center $d$ in time period $t\left(i l_{d p t}^{G S}\right)$ asthe ratio between the amount of product $p$ consumed in retail center $\mathrm{d}$ in this time period and the turnover ratio of retail center $d$ in time period $t\left(T_{O R}{ }_{d t}\right)$.

$i l_{d p t}^{G S}=\frac{\left(\sum_{p^{\prime} p^{\prime \prime}} \sum_{d p^{\prime \prime} p p^{\prime \prime} t}^{I-D}\right)}{T O R_{d t}^{D}} \forall d, p, t$

The inventory level of the retail centersis used to set bounds on the amount of product $p$ stored, using $\lambda_{\operatorname{MAX}}$ and $\lambda_{\text {MIN }}$ as factors related to the desired availability of the storage in Eqs (37) and (38). Our model assumes values of one and three for these factors, respectively.

$$
\begin{aligned}
& s p_{d p t}^{D} \leq \lambda_{M A X} i_{d p t}^{G S} \quad \forall d, p, t \\
& s p_{d p t}^{D} \geq \lambda_{M I N} i l_{d p t}^{G S} \quad \forall d, p, t
\end{aligned}
$$

\subsection{Retail Centers - Detailed Model}

The detailed model includes a description of gas stations inretail centers. In this model, each retail center represents a set of gas stations where the fuel is sold. To avoid the use of 0-1 variables for individual gas stations, we introduce integer variables to represent the number of gas stations of the same type, age and demand zone.

The equations take into account the fact that gas stations have different designs according to the number of products they can produce (single or multiproduct). The variables $w p^{I-D} d p^{\prime} p p^{\prime \prime} t$ and $w p^{O-D}$ dpt indicate the flows of product consumed and produced, respectively.The equations corresponding to the aggregated model (mass balances; demand and inventory equations - Eqs (30) to (38)) are also included in the detailed formulation.

Every gas station has a lifetime ${ }_{G}$, after which a retrofit must be performed to keep the gas station working. Otherwise, this gas station becomes inactive or idle.Figure5 shows a scheme to describe the modeling of the aging of gas stations. The dashed line divides the figure into two main parts: the one above represents the active gas stations (all the circles, except the last row) and the one below represents the inactive gas stations (the last row of circles). The rows represent the age $a$ of gas stations and the columns the yeartin the time horizon.

In this way, the thick arrows at the very top of Fig. 5represent the new gas stations that are added to the set of active ones. The arrows that connect all the active gas stations of a time period $t$ with the set of inactive gas stations in the same period of time (dotted arrows) represent those gas stations that have been closed. The lines that connect the circle of age $a$ and time period $t$ with the circle of age $a+1$ and time period $t+1$ (continuous lines) represent the aging of the gas stations. The arrows that connect the set of inactive gas stations in year $t$ with the circle in the very top in the same year (dashed arrows) represent the retrofit over inactive gas stations. Finally, the arrows that connect the set of inactive gas stations to each other throughout years (arrows of dots and dashes) represent the flow of gas stations that remain inactive from year $t$ 1 to year $t$. 


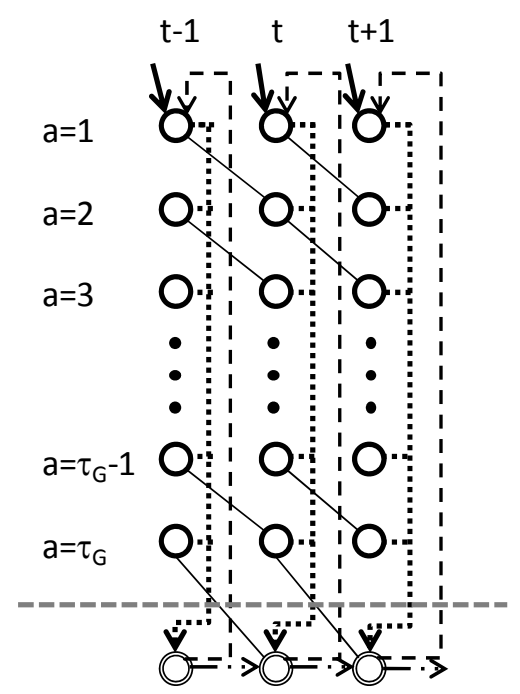

Fig. 5. Modeling of Gas Stations

Eqs. (39) and (40) represent inventory balances for active gas stations $\left(n_{d g t a}\right)$ and idle gas stations $\left(n_{d g t}^{I}\right)$ respectively. These groups can link to each other in the way that was explained above: closing an active gas station $\left(n^{D}\right.$ dgta); performing a retrofitto an idle gas station $\left(n_{d v t}^{R}\right)$ or just building a new one $\left(n^{N}{ }_{d g t}\right)$. Here, $n_{\text {dgta }}$ is the number of active gas stations of type $g$ andage $a$ within retail center $d$ in time period $t ; n_{d g t}^{I}$ is the number of inactive gas stations of type $g$ within retail center $d$ in time period $t ; n_{\text {dgta }}^{D}$ is the number of dropped off gas stations of type $g$ of age $a$ within retail center $d$ in time period $t$; $n^{R}{ }_{d v t}$ is the number of type $v$ retrofits that take place within retail center $d$ in time period $t$ and $n^{N}$ dgt is the number of new gas stations of type $g$ within retail center $d$ in time period $t$.The initial set of gas stations is specified $\left(\right.$ NINIT $\left._{\text {dga }}\right)$.

$$
\begin{array}{ll}
n_{\text {dgta }}=\left.\left(\left.N I N I T_{\text {dga }-1}\right|_{t=1}+\left.n_{\text {dgt }-1 a-1}\right|_{t>1}\right)\right|_{a>1}+\left.\left(\sum_{v \in G V O(g, v)}^{\sum n^{R} d v t}+n_{d g t}^{N}\right)\right|_{a=1}-n_{d g t a}^{D} & \forall d, g, t, a \\
n_{d g t}^{I}=\left.\sum_{a=\tau_{G}} N I N I T_{d g a}\right|_{t=1}+\left.n_{d g t-1}^{I}\right|_{t>1}+\sum_{a} n_{d g t a}^{D}+\left.\sum_{a=\tau_{G}} n_{d g t-1 a}\right|_{t>1}-\sum_{v \in G V I(g, v)} n^{R} d v t & \forall d, g, t
\end{array}
$$

Other important constraints for the gas stationsare those related to their capacity. The capacity is represented by both the storage capacity inthe underground tanks and the capacity of delivering product $p$ in each gas station.

The capacity of the underground tanks in gas stations is determined in Eqs. (41) and (42). Lower and upper bounds are imposed. They are related to the number of active gas stations of type gandage $a$ within retail center $d$ in time period $t$ $\left(n_{d g t a}\right)$, and to the use of a factor of maximum and minimum capacity of the underground tanks that store product $p$ in type $g$ gas stations within retail center $d,\left(S C_{d g p}^{M A X}\right.$ and $S C_{d g p}^{M I N}$ ). These bounds may correspond to safety considerations (Code of Federal Regulations 40 C.F.R Part 280). The subset $D P I(d, p)$ represents those products $p$ that are input in retail center $d$. 


$$
\begin{aligned}
& i l_{d p t}^{G S} \leq \sum_{a} \sum_{g \in G P I}(g, p) \\
& S C_{d g p}^{M A X} n_{d g t a} \quad \forall d, p \in D P I(d, p), t \\
& i l_{d p t}^{G S} \geq \sum_{a} \sum_{g \in G P I(g, p)} S C_{d g p}^{M I N} n_{d g t a} \quad \forall d, p \in D P I(d, p), t
\end{aligned}
$$

Thecapacity to deliver product $p$ in retail center $d$ in time period tmust be less than or equal to the total capacity of delivery of those gas stations that are able to produce product $p$. This fact is imposed by Eqs. (43) to (45). The variable ${ }^{N}{ }_{d g t}$ represents the equivalent quantity of gas stations of type $g$ that are under construction in retail center $d$ in time period $t$. This variable is subtracted in the capacity formula, because the gas stationsunder construction are not available to deliver fuel in the construction period.It is calculated in Eq. (46).

$$
\begin{aligned}
& w_{d p t}^{O-D} \leq \sum_{g \mid G P O(g, p)} P C_{d g}^{D}\left[\left(\sum_{a} n_{d g t a}\right)-c_{d g t}^{N}\right] \quad \forall d, p=\{E 10 ; E 30 ; E 85\}, t \\
& w_{d p t}^{O-D}+w_{d p^{\prime} t}^{O-D} \leq \sum_{g \mid \begin{array}{l}
G P O(g, p) \\
G P O\left(g, p^{\prime}\right)
\end{array}} P C_{d g}^{D}\left[\left(\sum_{a} n_{d g t a}\right)-c_{d g t}^{N}\right] \quad \forall d,\left\{p, p^{\prime}\right\}=\{\{E 10, E 30\} ;\{E 10, E 85\} ;\{E 30, E 85\}\}, t \\
& w_{d, E 10, t}^{O-D}+w_{d, E 30, t}^{O-D}+w_{d, E 85, t}^{O-D} \leq \sum_{g \mid \begin{array}{l}
G P O(g, E 10) \\
G P O(g, E 30) \\
G P O(g, E 85)
\end{array}} P C_{d g}^{D}\left[\left(\sum_{a} n_{d g t a}\right)-c_{d g t}^{N}\right] \forall d, t \\
& c_{d g t}^{N}=\sum_{v \in G V O}\left(P T O_{d v t}^{V} n_{d v t}^{R}\right)-\left(P T O_{d g t}^{G} n_{d g t}^{N}\right) \quad \forall d, g, t
\end{aligned}
$$

The factor $P T O_{d g t}^{G}$ represents the percentage of the time period $t$ during which a gas station of type $g$ within retail center $d$ is being built (from new). In a very similar way, $P T O_{d v t}^{V}$ can be defined for the retrofitted gas stations. With these factors we define the capacity under construction of type $g$ within retail center $d$ in time period $t$.

If a gas station exists, it must deliver at least a minimumamount of fuel. To take this fact into account, a lower bound on the amount of fuel delivered is imposed in Eqs (47) and (48).

$$
\begin{aligned}
& w_{d p p p t}^{I-D} \geq 0.50 P C_{d g}^{D} \sum_{a} n_{d g t a} \quad \forall d,\{p, g\}=\{\{E 10, G 1\},\{E 30, G 2\}\}, t \\
& w_{d, E 10, E 10, E 85, t}^{I-D}+w_{d, E 30, E 10, E 85, t}^{I-D}+w_{d, E 85, E 10, E 85, t}^{I-D} \geq 0.50 P C_{d^{\prime} G 3^{\prime}}^{D} \sum_{a} n_{d^{\prime} G 3^{\prime} t a} \quad \forall d, t
\end{aligned}
$$




\subsection{Objective Function}

The investment cost for the different stages of the supply chain is calculated with Eqs. (49) - (53) as follows:

$$
\begin{aligned}
& c^{I N V}=\sum_{t}\left[\sum_{i} t i c_{i t}^{H S}+\sum_{j} t i c_{j t}^{E P}+\sum_{k} t i c_{k t}^{D C}+\sum_{d} t i c_{d t}^{G S}\right] \\
& t i c_{i t}^{H S}=\sum_{b} F I C_{i}^{H S} y_{b i t}^{I}+V I C_{i}^{H S} b h s_{b i t} \quad \forall i, t \\
& \operatorname{tic}_{d t}^{G S}=\sum_{v} F C R_{d v} n_{d v t}^{R}+\sum_{g} F C N_{d g} n_{d g t}^{N} \quad \forall d, t \\
& t i C_{j t}^{E P}=\sum_{q} \sum_{s}\left[F I C_{j q s-1}^{E P} y_{j q s t}^{J}+\left(n p c_{j q s t}^{J}-P C_{j q s-1}^{E P} y_{j q s t}^{J}\right) \frac{F I C_{j q s}^{E P}-F I C_{j q s-1}^{E P}}{P C_{j q s}^{E P}-P C_{j q s-1}^{E P}}\right] \quad \forall j, t \\
& t i c_{k t}^{D C}=\sum_{s}\left[F I C_{k s-1}^{D C} y_{k s t}^{K}+\left(n p c_{k s t}^{K}-P C_{k q s-1}^{D C} y_{k s t}^{K}\right) \frac{F I C_{k s}^{D C}-F I C_{k s-1}^{D C}}{P C_{k s}^{D C}-P C_{k s-1}^{D C}}\right] \quad \forall k, t
\end{aligned}
$$

For the investment cost in harvesting sites, defined in Eq. (50), fixed and variable cost coefficients are used. For the investment in gas stations, defined in Eq. (51), two fixed costs are usedcorresponding to retrofits of gas stations $\left(F C R_{d v}\right)$ or construction of new ones $\left(F C N_{d g}\right)$. No variable cost is includedbecauseonly one size is considered in investments on gas stations. For the remaininginvestment costs, defined in Eqs (52) and (53), the variable cost coefficients are implicitly involved (You and Wang, 2011; You et al., 2012).

The processing and maintenance cost is also calculated with a variable and a fixed cost for each industry involved in the supply chain (Eq. (54)) (You and Wang, 2011).

$$
\begin{aligned}
c^{P R}=\sum_{t}\left[\sum_{i}\left(\alpha_{i t}^{H S} t i c_{i t}^{H S}+\sum_{b} V P C_{b i t}^{I} b h s_{b i t}\right)+\sum_{j}\left(\alpha_{j t}^{E P} t i C_{j t}^{E P}+\sum_{p} \sum_{q} V P C_{j q t}^{J} w_{j p q t}^{O-J}\right)+\right. \\
\\
\left.\sum_{k}\left(\alpha_{k t}^{D C} t i c_{k t}^{D C}+\sum_{p} \sum_{q} V P C_{k t}^{K} w_{k p t}^{O-K}\right)+\sum_{d}\left(\alpha_{d t}^{G S} t i c_{d t}^{G S}+\sum_{d} \sum_{p} V P C_{d p t}^{D} w_{d p t}^{O-D}\right)\right]
\end{aligned}
$$

The cost of transportation in Eq. (55), is calculated as the summation of fixed and variable costs(regarding distance) over all the possible connections in the supply chain by all the feasible transportation modes and in all time periods (You and Wang, 2011). 


$$
\begin{aligned}
c^{T R}=\sum_{t} \sum_{m} & {\left[\left(\sum_{b} \sum_{i} \sum_{j} F T C_{b m t}^{B}+V T C_{b m t}^{B} D_{i j m}^{I J}\right) q b_{b i j m t}^{I J}+\left(\sum_{p} \sum_{j} \sum_{k} F T C_{p m t}^{P}+V T C_{p m t}^{P} D_{j k m}^{J K}\right) q p_{j k m p t}^{J K}+\right.} \\
& \left(\sum_{p} \sum_{j} \sum_{f} F T C_{p m t}^{P}+V T C_{p m t}^{P} D_{f j m}^{F J}\right) q p_{f j m p t}^{J F}+\left(\sum_{p} \sum_{k} \sum_{l} F T C_{p m t}^{P}+V T C_{p m t}^{P} D_{k l m}^{K L}\right) q g_{k l m p t}^{L K}+ \\
& \left.\left(\sum_{p} \sum_{d} \sum_{k} F T C_{p m t}^{P}+V T C_{p m t}^{P} D_{d k m}^{D K}\right) q p_{d k m p t}^{K D}\right]
\end{aligned}
$$

Finally, storage cost is computed from Eq. (56). Eq. (57) calculates the purchase cost of the gasoline required to perform the blending (we use the wholesale price).

$$
\begin{aligned}
& c^{S T}=\sum_{t}\left[\sum_{b} \sum_{j} S C_{b j t}^{B J} s b_{b j t}^{J}+\sum_{b} \sum_{j} S C_{j p t}^{P J} s p_{j p t}^{J}+\sum_{k} \sum_{p} S C_{k p t}^{P K} s p_{k p t}^{K}+\sum_{d} \sum_{p} S C_{d p t}^{P D} s p_{d p t}^{D}\right] \\
& c^{P U}=\sum_{k} \sum_{l} \sum_{m} \sum_{p} \sum_{t} C G_{l t} q g_{k l m p t}^{L K}
\end{aligned}
$$

The objective function is calculated as the summation over the previously described costs asshown in Eq. (58).

$$
\min c=c^{I N V}+c^{P R}+c^{T R}+c^{S T}+c^{P U}
$$

\section{Examples}

We have formulated two models as stated in Section 3. The first one is an aggregated model that is described by Eqs. (1) to (38) and (49) to (58), in which the retail center formulation has no details about how the fuel is distributed to customers. And the second one is a detailed model described by Eqs. (1) to (58), in which the retail center formulation includes information about gas stations in each region.

The time horizon for both problems is 20 years with periods of 4 months for the first 10 years, and periods of 6 months for the next 10 years, requiring a total of 50 time periods.Each retail center represents one county of Alabama state. The fuel demand is estimated based on the population of each county and the gasoline consumption of the entire county (US DOE, EERE, apps1.eere.energy.gov/states/transportation.cfm/state $=\mathrm{AL}$ and 2002 Economic Census).Figure 6 shows total fuel demand profile for Alabama state in the next 20 yearstime horizon. We consider that the normal growth of the number of cars throughout the time is reflected in an initial increase of demand, but in the middle term this effect is roughly balanced with the increase of engine efficiency. And the decrease at the end of the time horizon is due to a further increase of energy efficiency and/or the possibility to use another energy source for transportation.

Figure 7 shows the nodes in the potential supply chain. The shadowed region (AL state) represents the place where one retail center per county is considered. The profile of the demand for E10, E30 and E85 is shown in Tables 3 and 4. Table 3 shows the total demand of fuel estimated by the gasoline consumption per year per capita reported in US 2000 census (2002 Economic Census, US DOE EERE). 


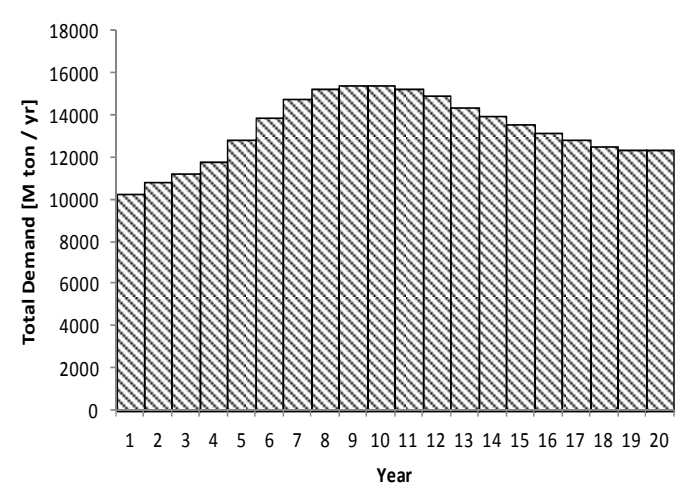

Fig. 6. Total fuel Demand in Alabama State [M ton / yr]

The estimation in Table 3 is for the first year of the time horizon, and in the subsequent years the demand is increased. While in the last year of the time horizon the demand is $20 \%$ higher than the value in the first year, in the middle term it has a peak of $50 \%$ of the value in the first year.

Table 4 shows the percentage of the total demand that correspond for each fuel blend.

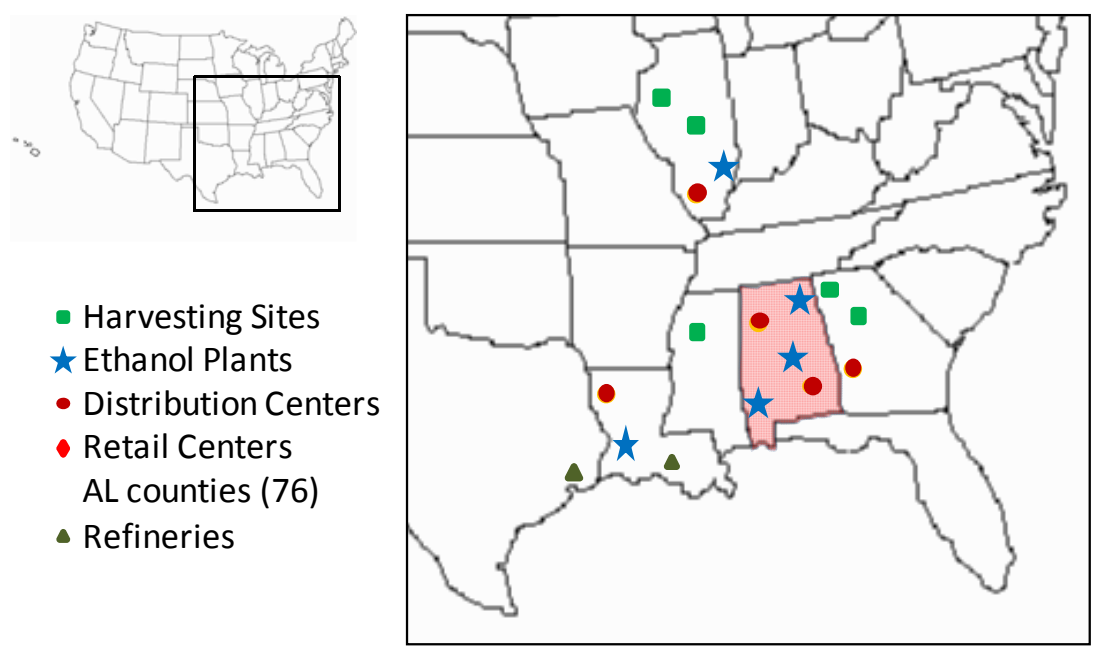

Fig. 7. Potential locations for the nodes of the supply chain 
Table 3. Total demand of fuel in the first year of the time horizon

\begin{tabular}{|c|c|c|c|c|c|}
\hline County & $\begin{array}{c}\text { Gasoline } \\
\text { Consumption } \\
\text { [ton/yr] }(2005)\end{array}$ & County & $\begin{array}{c}\text { Gasoline } \\
\text { Consumption } \\
\text { [ton/yr] }(2005)\end{array}$ & County & $\begin{array}{c}\text { Gasoline } \\
\text { Consumption } \\
\text { [ton/yr] (2005) }\end{array}$ \\
\hline Autaga & 90,136 & Dallas & 72,378 & Marengo & 34,731 \\
\hline Baldwin & 301,050 & DeKalb & 117,452 & Marion & 50,833 \\
\hline Barbour & 45,351 & Elmore & 130,986 & Marshall & 153,641 \\
\hline Bibb & 37,849 & Escambia & 63,292 & Mobile & 682,145 \\
\hline Blount & 94,680 & Etowah & 172,489 & Monroe & 38,102 \\
\hline Bullock & 18,027 & Fayette & 28,477 & Montgomery & 378,843 \\
\hline Butler & 34,598 & Franklin & 52,366 & Morgan & 197,364 \\
\hline Calhoun & 195,847 & Geneva & 44,249 & Perry & 17,493 \\
\hline Chambers & 56,513 & Greene & 14,940 & Pickens & 32,615 \\
\hline Cherokee & 42,926 & Hale & 26,031 & Pike & 54,340 \\
\hline Chilton & 72,086 & Henry & 28,578 & Randolph & 37,846 \\
\hline Choctaw & 22,891 & Houston & 167,727 & Rusell & 87,453 \\
\hline Clarke & 42,669 & Jackson & 87,916 & St.Clair & 138,072 \\
\hline Clay & 23,012 & Jefferson & $1,087,599$ & Shelby & 322,225 \\
\hline Cleburne & 24,729 & Lamar & 24,056 & Sumter & 22,733 \\
\hline Coffee & 82,500 & Lauderdale & 153,129 & Talladega & 135,921 \\
\hline Colbert & 89,900 & Lawrence & 56,718 & Tallapoosa & 68,738 \\
\hline Conecuh & 21,849 & Lee & 231,648 & Tuscaloosa & 321,516 \\
\hline Coosa & 19,059 & Limestone & 136,732 & Walker & 110,703 \\
\hline Covington & 62,377 & Lowndes & 18,663 & Washington & 29,039 \\
\hline Crenshaw & 22,969 & Macon & 35,433 & Wilcox & 19,276 \\
\hline Cullman & 132,808 & Madison & 553,013 & Winston & 40,441 \\
\hline Dale & 83,000 & & & & \\
\hline
\end{tabular}

Table 4. Percentage of the total demand for each blend

\begin{tabular}{|c|c|c|c|c|c|}
\hline Ylend & $1-2$ & $3-5$ & $6-10$ & $11-15$ & $16-20$ \\
\hline E10 & 80 & 68 & 50 & 35 & 22 \\
\hline E30 & 15 & 25 & 35 & 40 & 43 \\
\hline E85 & 5 & 7 & 15 & 25 & 35 \\
\hline
\end{tabular}


The main data are shown in Table 5 and Fig. 8. Table 5 shows the yield of ethanol from biomass (Martin and Grossmann, 2012; Wei et. al, 2009). Figure 8 shows data for investment size and cost (Martin and Grossmann, 2012) and the projection with the six tenth rule.

Table 5. Yields of Ethanol Technologies [ton Ethanol / ton biomass]

\begin{tabular}{ccc}
\hline & Switchgrass & Wood Chips \\
\hline Biochemical & 0,28 & 0,17 \\
Thermochemical & 0,20 & 0,19 \\
Hybrid & 0,33 & 0,26 \\
\hline
\end{tabular}

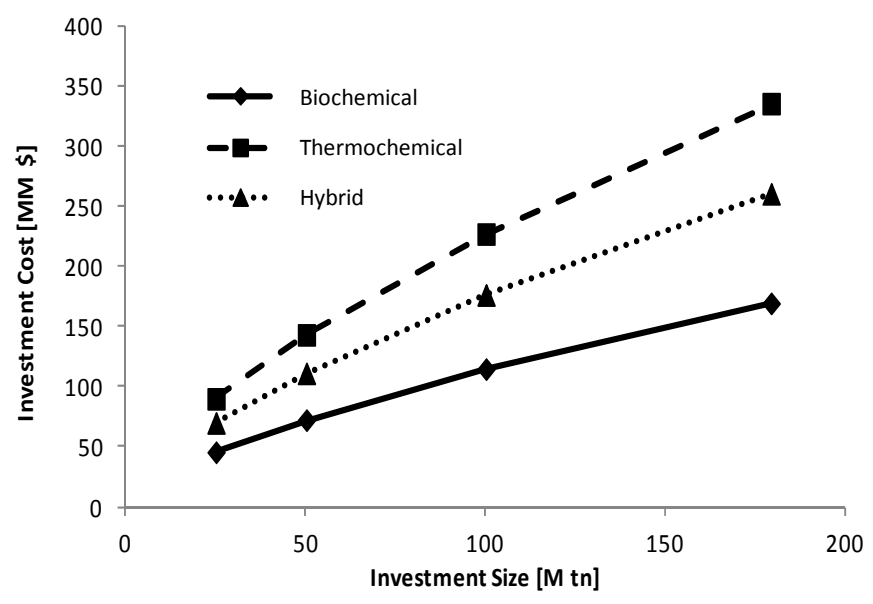

Fig 8. Investments on different Ethanol technologies

In this section, one example is solved with both models. These examples are solved with CPLEX12.4 in GAMS (Brooke et al., 2011)

\subsection{Aggregated Model Example}

This example is solved for the state of Alabama with the 67 counties shown in Table 3 . We consider 5 harvesting sites with2 raw materials (wood chips and switchgrass), 5 ethanol plants with 3 feasible production technologies, 2 petroleum refineries, 5 distribution centers and 67 retail centers (one for each AL county).

The results can be summarized as follows. As shown in Fig. 9, three out of five potential locations for harvesting sites are selected. In these harvesting sites, switchgrass is sown. The optimal solution includes investment in three potential locations for ethanol plants according to Table 6. The location of these ethanol plants are shown as stars in Fig. 9. 


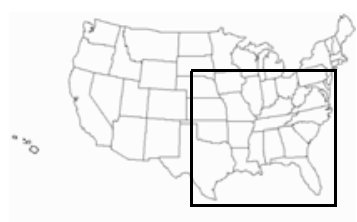

- Harvesting Sites

$\star$ Ethanol Plants

- Distribution Centers

- Retail Centers

AL counties (76)

- Refineries

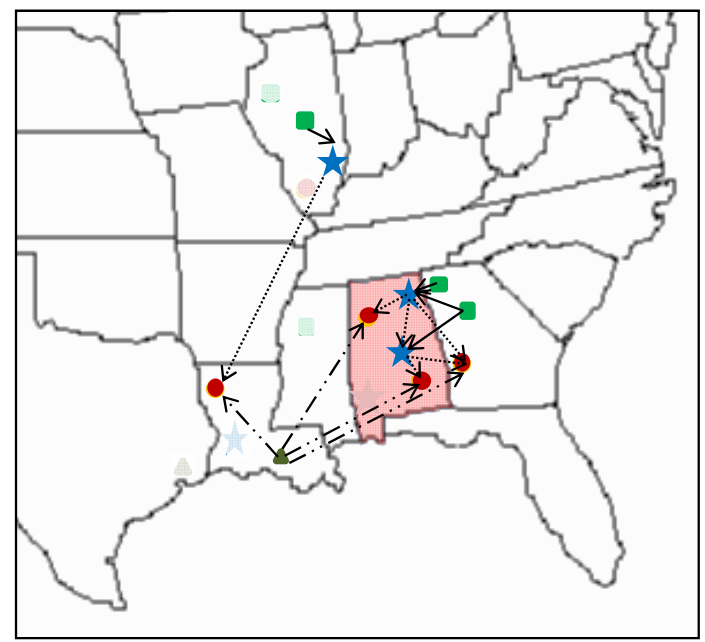

Fig. 9. Optimal locations for the nodes of the supply chain

Table 6. Ethanol Plants built over 20- yearshorizon

\begin{tabular}{|c|c|c|c|}
\hline Carmi[IL] & \multicolumn{3}{|c|}{ Number of Plants / Capacity [M ton / yr] } \\
\hline Year & Biochemical & Thermochemical & Hybrid \\
\hline 1 & $2 / 280$ & $1 / 180$ & \\
\hline 6 & & & $3 / 540$ \\
\hline TOTAL & $2 / 280$ & $1 / 180$ & $3 / 540$ \\
\hline Scottsboro $[\mathrm{AL}]$ & \multicolumn{3}{|c|}{ Number of Plants / Capacity [M ton / yr] } \\
\hline Year & Biochemical & Thermochemical & Hybrid \\
\hline 1 & $2 / 330$ & $1 / 180$ & $2 / 350$ \\
\hline 4 & & & $3 / 510$ \\
\hline 9 & & & $1 / 180$ \\
\hline 11 & & & $3 / 460$ \\
\hline TOTAL & $2 / 330$ & $1 / 180$ & $9 / 1,500$ \\
\hline Montgomery [AL] & \multicolumn{3}{|c|}{ Number of Plants / Capacity [M ton / yr] } \\
\hline Year & Biochemical & Thermochemical & Hybrid \\
\hline 1 & $2 / 265.8$ & $1 / 180$ & \\
\hline 11 & & & $3 / 460$ \\
\hline TOTAL & $2 / 265.8$ & $1 / 180$ & $3 / 460$ \\
\hline
\end{tabular}


Figure 10 shows the integrated supply chain for fuel distribution to the retail centers in the state of Alabama. It can be noted that the distribution center located in the state of Louisiana (LA2) provides the southwest of AL with fuel (first map), and the distribution center located in the state of Georgia (GA3) provides fuel to the east of AL State (last map). The rest of retail centers in this stateare supplied by distribution centers within the same state (the distribution centerAL4 provides the region in the second map and AL5 provides the region in the third map).

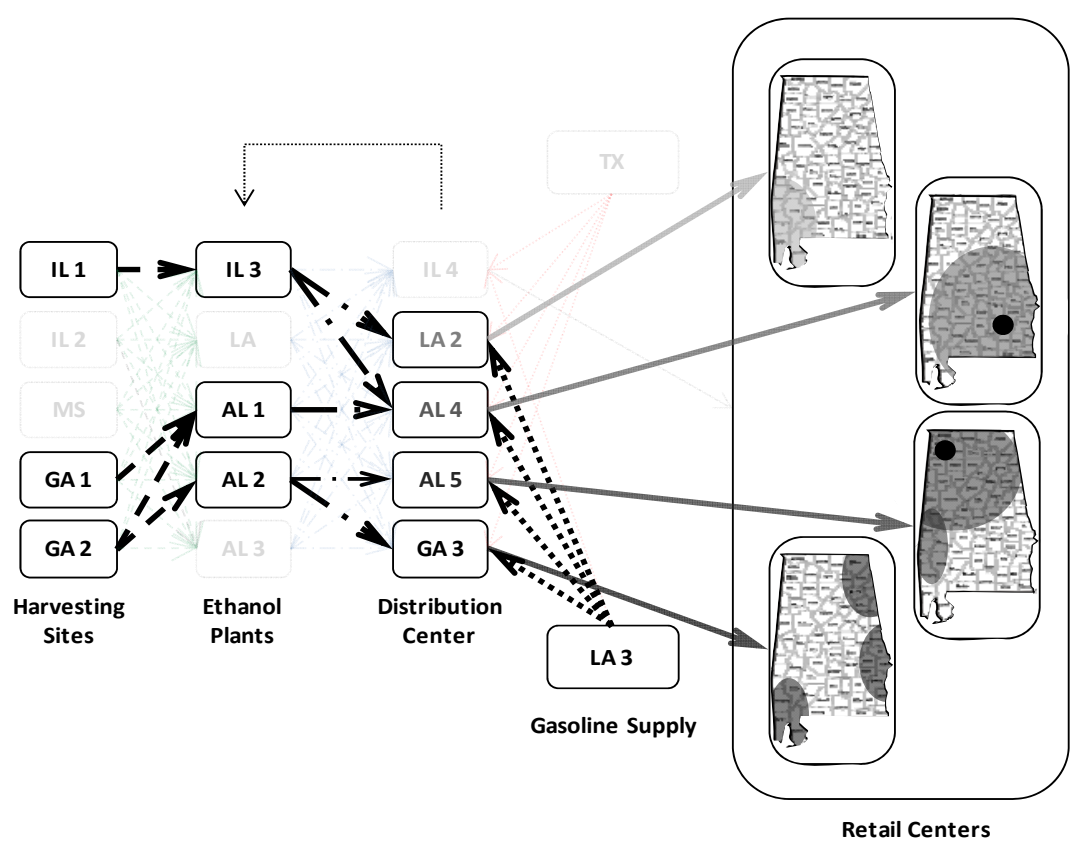

Fig. 10. Optimal connections between the nodes of the supply chain

The price of fuels with higher content of ethanol is lower than the retail price of fuels with lower content of ethanol. For that reason, we consider a lower production cost for blends with higher ethanol content. We have also considered blending pumps associated to the commercialization of E85 in retail centers. Because of that and because of the entire cost of blends, Figure 11 shows that sales are as follows: the demand of E10 is fully satisfied with E10 blend; sales of E85 satisfies only the $50 \%$ of its demand, and the demand is fully satisfied with lower ethanol blends; and sales of E30 at the beginning of the time horizon are at the minimum level too (50\% of the demand).However, throughout the time horizon sales of E30 increase with respect to its demand in order to partially satisfy the E85 demand. In summary, ethanol consumption increases as compared to gasoline consumption, to meet the demand. 

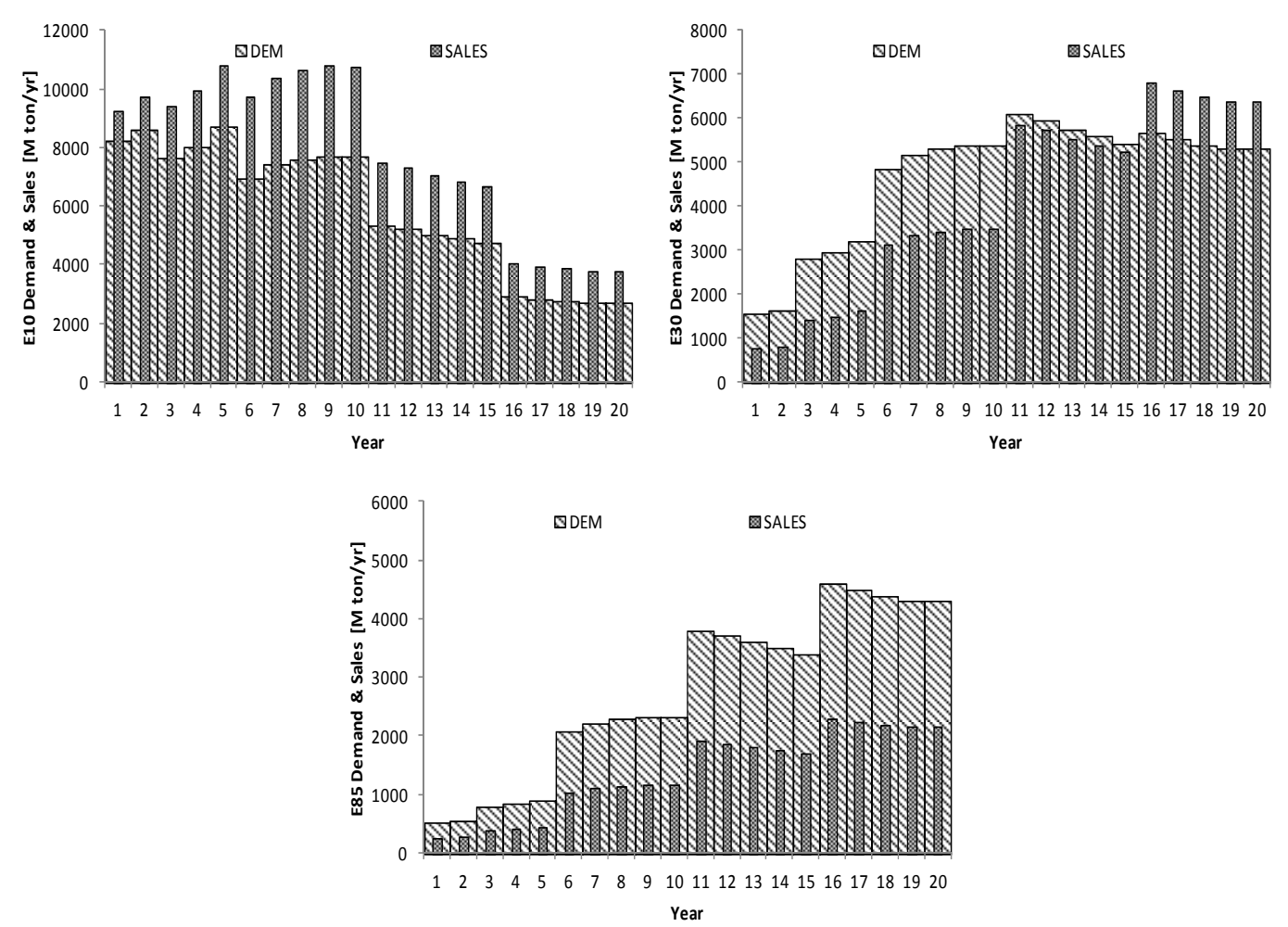

Fig. 11. Demand and sales of fuel blends in Alabama State [M ton / yr]

The computational results are shown in Table 7, where it can be seen that the model was solved in about 5 minutes CPU time with an optimality gap of less than $1 \%$.

Table 7. Computational Results for Aggregated Model

\begin{tabular}{cc}
\hline Solver & CPLEX 12.4 \\
Equations & 109,363 \\
Variables & 136,223 \\
Discrete Variables & 1,400 \\
Total Cost [MM USD] & $140,282.7$ \\
Solution Time [sec] & 332.5 \\
Gap [\%] & 0.5329 \\
\hline Processor: Intel Core i7-2640M 2.80GHz-8GB RAM
\end{tabular}

\subsection{Detailed Model Example}

This example is solved as the previous onefor 5 harvesting sites with2 raw materials (wood chips and switchgrass), 5 ethanol plants with 3 feasible production technologies, 2 petroleum refineries and 5 distribution centers. We consider 67 retail centers (one for each AL county) and we consider the number of different types of existing gas stations for each one of them. As before, the time horizon is 20 years. 
As we described in Section 3 (Problem Statement), the difference betweenthe aggregated and the detailed model is in the retail center formulation. Therefore, the data provided in Section 5 are valid for the detailed model. Additional data for the detailed modelinclude the initial number of gas stations in each county of AL state. Theinformation on the number of gas stations in each county is obtained from 2002 Economic Census,and has been updated to 2012 asa linear function of populationgrowth. We have indicated the total number of gas stations according to their age. Table 8 shows the initial number of gas stations for some counties as an example.

Table 8. Initial Number of Gas Stations in Alabama State (detail of three counties)

\begin{tabular}{|c|c|c|c|c|c|c|c|c|c|c|c|}
\hline \multirow{2}{*}{ Type } & \multicolumn{11}{|c|}{ Age } \\
\hline & 1 & 2 & 3 & 4 & 5 & 6 & 7 & 8 & 9 & 10 & TOT \\
\hline & \multicolumn{11}{|c|}{ Autaga county } \\
\hline G1 (E10) & 4 & 7 & 1 & 5 & 1 & 5 & 2 & 1 & 4 & 4 & 34 \\
\hline G2 (E30) & 1 & & & 1 & & 1 & 1 & & & & 4 \\
\hline \multirow[t]{2}{*}{ G3 (All) } & 1 & & & & 1 & & & & & & 2 \\
\hline & \multicolumn{10}{|c|}{ Baldwin county } & \\
\hline G1 (E10) & 2 & 11 & 11 & 25 & 22 & 22 & 22 & & 5 & 12 & 132 \\
\hline G2 (E30) & 1 & & 2 & 3 & 2 & & & 3 & 2 & 3 & 16 \\
\hline \multirow[t]{2}{*}{ G3 (All) } & 4 & 1 & 2 & 1 & & & & & & & 8 \\
\hline & \multicolumn{10}{|c|}{ Monroe county } & \\
\hline G1 (E10) & 1 & 2 & 2 & 3 & & 1 & 1 & & 2 & 1 & 13 \\
\hline G2 (E30) & & 1 & & & 1 & & & & & & 2 \\
\hline \multirow[t]{2}{*}{ G3 (All) } & 1 & & & & & & & & & & 1 \\
\hline & \multicolumn{10}{|c|}{ Talladega county } & \\
\hline G1 (E10) & 1 & 7 & 3 & 8 & 2 & 8 & 2 & 3 & 9 & 9 & 52 \\
\hline G2 (E30) & 1 & & & 1 & & 1 & 1 & & & 1 & 5 \\
\hline \multirow[t]{2}{*}{ G3 (All) } & 1 & & 2 & & & & & & & & 3 \\
\hline & \multicolumn{10}{|c|}{ ALABAMA STATE } & \\
\hline G1 (E10) & 323 & 263 & 280 & 268 & 304 & 276 & 294 & 218 & 217 & 276 & 2,719 \\
\hline G2 (E30) & 26 & 31 & 40 & 41 & 32 & 26 & 37 & 32 & 29 & 21 & 315 \\
\hline G3 (All) & 48 & 34 & 31 & 16 & 5 & & & & & & 134 \\
\hline
\end{tabular}

The results obtained in the detailed model are similar to those obtained with the aggregated one (previous section). However, it is worth to point out the change in the number of gas stations involved in the supply chain as a function of time. Figure 12 shows the time profile of number and type of gas stations throughout the 20 year time horizon. While in the first years the number of G1 (E10) gas stations remains almost constant, the major change occurs in the middle part of the time horizon, when the number of G1 (E10) gas stations decrease. By this time the number of G2 (E30) and G3 (E10, E30, E85) gas stations increase mainly due to retrofits on G1 (E10) gas stations. 


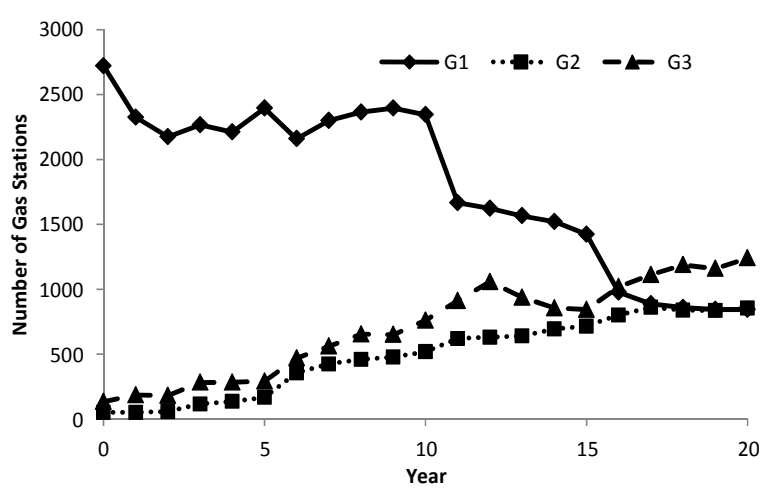

Fig. 12. Time profile of total number of gas stations in AL state

The information displayed in Fig. 12 can be useful to obtain an investment plan over gas stations in order to satisfy the predicted demand of blends. Even though this plan does not contain information about which gas station may be subjected to retrofit, it provides information about the number of gas stations that should be retrofitted within each county considered in the model.

The gas stations that have blending pumps can in principle provide any product. Therefore, each G3 gas station can sellany blend. As anexample, we include two figures with results obtained for Jefferson and Monroe counties. Figure 13shows totaldemand and the salesof each blend in G3 gas stationsfrom Jefferson county throughoutthe 20 year time horizon. Most of the E10 demand is satisfied with G1 gas stations, but almost all E30demand is satisfied with multiproduct gas stations (G3). It can be concluded that new multiproduct gas stations are not selected to provide the market with E10 (because the infrastructure for this blend is already developed). Regarding E85 sales, only 50\% of total demand is produced; the amount of demand which is not satisfied with this blend is mostly satisfied with E10. On the other hand, given that the demand of fuel in the near future will be composed by several blends, it is more convenient to install multiproduct gas stations instead of single product gas stations for different blends.

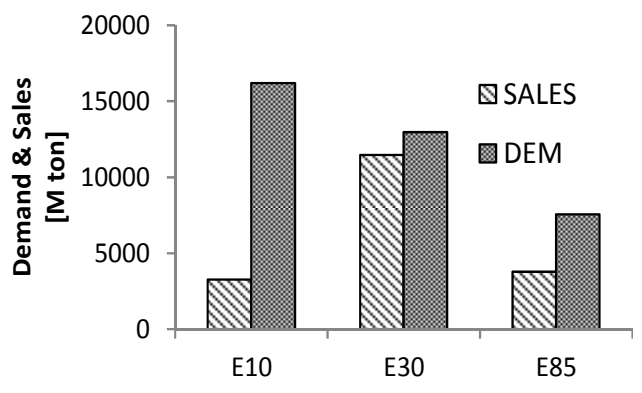

Fig. 13. Demand and sales in multiproduct gas stations within Jefferson county

Figure 14 shows the time profile for the production of each blend in multiproduct gas stations within Monroe county, throughout the 20 years time horizon. We can conclude that the production of E30 and E85 in multiproduct gas stations within Monroe county increases with time and the production of E10 decreases with time.

Throughout time horizon the number of G1 gas stations is reduced (see Fig. 12). Then, most of E10 consumed is provided by G3 gas stations (see Fig. 15). 


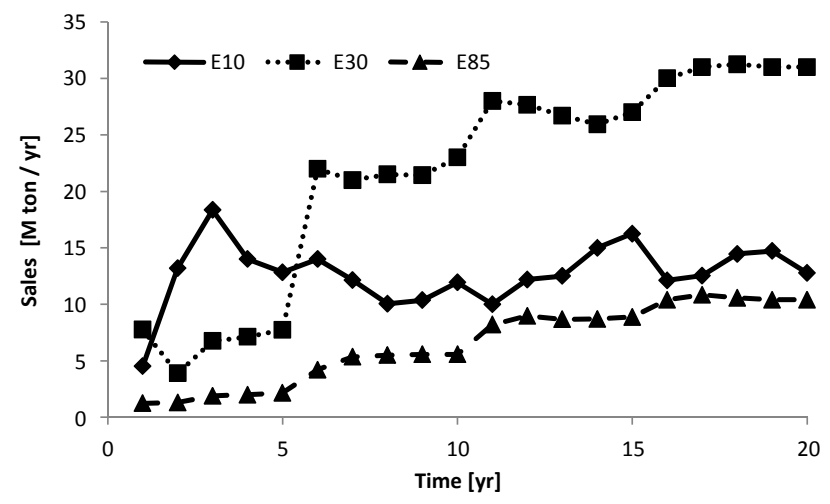

Fig. 14. Time profile for the sales of multiproduct gas stations within Monroe county

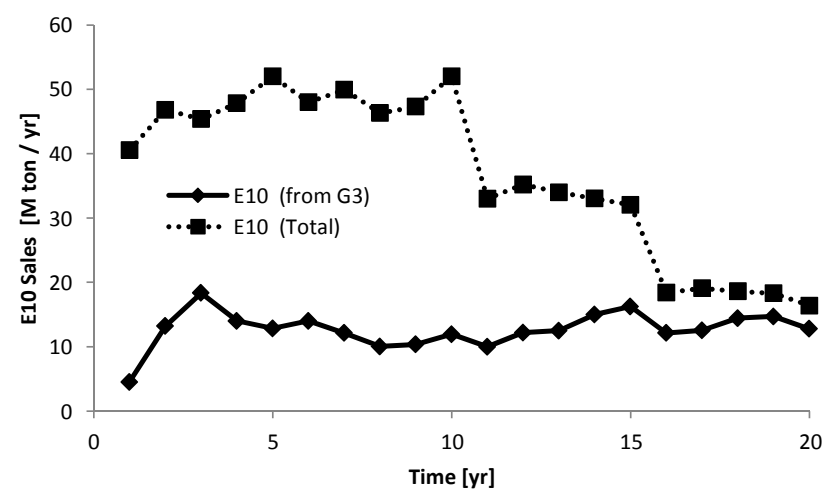

Fig. 15. Time profile for E10total sales and the sales of E10 in multiproduct gas stations within Monroe county

In the detailed model, which considers integer variables for gas stations in each one of the $67 \mathrm{AL}$ counties, and taking into account an initial set of almost 3,500 gas stations, it becomes a challenge to obtain a solution within reasonable time. As shown in Table 9, the solution time for this MILP problem is more than 3 hours to reach an optimality gap of $1 \%$.

Table 9. Computational Results for Detailed Model

\begin{tabular}{cc}
\hline Solver & CPLEX 12.4 \\
Equations & 211,875 \\
Variables & 240,745 \\
Discrete Variables & 53,660 \\
Total Cost [MM USD] & $165,414.2$ \\
Solution Time [sec] & $11,856.2$ \\
Gap [\%] & 1.00 \\
\hline Processor: Intel Core i7-2640M 2.80GHz - 8GB RAM
\end{tabular}

We can note that the difference in the objective function between aggregated and detailed model is due tothe cost of the gas stations. In the detailed model, we take into account costs on gas stations that are not considered in the aggregated model, such asinvestment costs in the new and retrofitted gas stations. 
On the other hand, the number of discrete variables in the detailed modelis 97,880. However, as certain integer variables $\left(n_{\text {dgta }}\right.$ and $\left.n_{d g t}^{I}\right)$ are calculated with an equation that involves only integer variables and integer coefficients, they can be defined as continuous variables ranging between 0 and 1 . Therefore, the number of discrete variables is reduced to 53,660 which is still much larger than the 1,400 discrete variables in the aggregated model. Since the computational time is quite large (11,856 CPUs), this motivates the use of a bilevel decomposition method that is described in the supplementary material.In this scheme the problem is decomposed into an upper level problem that makes the decisions on the selection of major nodes in the supply chain, and into a lower level problem that is concerned with the detailed retrofit design of the gas stations. The proposed bilevel decomposition reduces the computational time to 7,137 CPUs, yielding a computational saving of about $40 \%$.

\section{Conclusions}

In this work, we have proposed anMILP model for the gasoline and ethanol supply chain, including harvesting sites to retail centers. Different levels of detail are included within a superstructure. We have formulated two models, an aggregated one that considers the fuel demand per county, and a detailed model that also considers the number of gas stations needed to satisfy the fuel demand in each county. Gas stations details are considered within retail centers formulation. In the latter model, the need for retrofit projects, blending pumps and new gas stations are easily detected. Five potential locations and three ethanol technologies are included for ethanol plants: biochemical, thermochemical and hybrid. Numerical results show that the hybrid process is as competitive as biochemical and thermochemical processes (larger yield and higher costs).Distribution centers receive pure ethanol and/or E85 from ethanol plants and gasoline from refineries, and they are able to produce any required blend. For simplicity, this paper takes into account only E10, E30 and E85, but the model can be easily extended to any other set of fuel blends.

In this sense,we have considered different types of gas stations: those that can commercialize only one type of blend and those that can commercialize every blend with the use of blender pumps. Future trends predicted by the model indicate that single blend gas stations will be replaced by multiple blend gas stations, with blender pumps. Optimal results indicate that most gas stations work during their entire lifetime (10 years) before any retrofit is carried out. However, at the beginning of the time horizon, many gas stations that can only provide E10 to the market are retrofitted to provide multiple blends to the market with the addition of a blender pump.

Finally, we have proposed a bilevel decomposition algorithm (see Supplementary material) which first solves a strategic planning model that takes the more general decisions and iteratively uses this solution to bound a more detailed model. Computational time is roughly reduced in almost $40 \%$.

\section{Acknowledgments}

The authors are grateful to Dr. Rathin Datta from Coskata who motivated this work. The authors also gratefully acknowledgethe Center for Advanced Process Decision-making,Ministry of Science of Technology and Innovation of Argentinaand the "Universidad Nacional del Sur" for the support of this work. 


\section{References}

1. 2002 Economic Census, http://www.census.gov/epcd/ec97/al/AL001.HTM

2. 40 C.F.R Part 280 - Technical standards and corrective action requirements for owners and operators of underground storage tanks. Code of Federal Regulations. http://law.justia.com/cfr/title40/40-26.0.1.1.9.html\#40:26.0.1.1.9.2.47.1

3. Akgul O., Shah N., Papageorgiou L. An optimisation framework for a hybrid first/second generation bioethanol supply chain. Computers and Chemical Engineering. 2012; 42:101-114

4. An H., Wilhelm W.E., Searcy S.W. Biofuel and petroleum-based fuel supply chain research: A literature review. Biomass and Bioenergy. 2011; 35 (9):3763-3774

5. Andersen F., Iturmendi F., Espinosa S., Díaz S. Optimal design and planning of biodiesel supply chain with land competition, Computers \& Chemical Engineering. 2012; 47:170-182.

6. Anderson S. The demand for ethanol as a gasoline substitute. Journal of Environmental Economics and Management. 2012; 63:151-168

7. Aslani, M., Alesheikh, A. Site selection for small gas stations using GIS. Scientific Research and Essays. 2011; 6 (15):1361-1371

8. Brinckerhoff P. Alternative Fuels Corridor Economic Feasibility Study. 2009. Washington State Department of Transportation.

9. Brooke A., Kendrick D., Meeraus A., Raman R. 2011. GAMS, A User Guide

10. Datta R., Maher M., Jones C., Brinker R. Ethanol - the primary renewable liquid fuel. J Chem Technol Biotechnol. $2011 ; 86: 473-480$

11. Douglas, J. Conceptual Design of Chemical Processes. 1988. McGraw Hill

12. Eksioglu S., Acharya A., Leightley L., Arora S. Analyzing the design and management of biomass-to-biorefinery supply chain. Computers and Industrial Engineering. 2009; 57:1342-1352.

13. Energy Independence and Security Act of 2007. In: RL34294, P.L. 110-140 ed. 2007

14. Grossmann, I.E. Enterprise-wide optimization: A new Frontier in process systems engineering. AIChE Journal. 2005; $51: 1846-1857$.

15. Grossmann, I.E. Advances in mathematical programming models for enterprise-wide optimization. Computers \& Chemical Engineering. 2012; 47: 2-18.

16. Guillén-Gosálbez, G., Mele, F. D. and Grossmann, I. E. A bi-criterion optimization approach for the design and planning of hydrogen supply chains for vehicle use. AIChE Journal. 2010; 56:650-667

17. Guillén-Gosálbez G., Grossmann I.E. A global optimization strategy for the environmentally conscious design of chemical supply chains under uncertainty in the damage assessment model. Computers and Chemical Engineering. 2010; 34:42-58

18. Guillén-Gosálbez G., Grossmann I.E. Optimal design and planning of sustainable chemical supply chains under uncertainty. AIChE Journal. 2009; 55:99-121.

19. Hussain R., Assavapokee T., Khumawala B. Supply Chain Management in the Petroleum Industry: Challenges and Opportunities. International Journal of Global Logistics \& Supply Chain Management. 2006; 1(2):90-97

20. Iyer R., Grossmann I.E. A Bilevel Decomposition Algorithm for Long-Range Planning of Process Networks. Ind. Eng. Chem. Res.1998; 37:474-481.

21. Jackson J., Grossmann I.E. High Level Optimization Model for the Retrofit Planning of Process Networks, Ind. Eng. Chem. Res. 2002; 41:3762-3770.

22. Mahmudi H., Flynn P.C. Rail vs truck transport of biomass. Appl Biochem Biotechnol. 2006 Spring ; 129-132:88103

23. Martin M., Grossmann I. Systematic syhthesis of sustainable biorefineries: A review. To appear in JEC Res. (2012)

24. National Biofuels Action Plan. Biomass Research and Development Board: US Department of Agriculture and US Department of Energy: 2008

25. Neiro S., Pinto J. A general modeling framework for the operational planning of petroleum supply chains. Computers and Chemical Engineering. 2004; 28:871-896

26. NREL, The Impact on Ethanol Blending on US Gasoline Prices, 2008, NREL/SR-670-44517.

27. Pacini H., Silveira S. Consumer choice between ethanol and gasoline: Lessons from Brazil and Sweden. Energy Policy. 2011; 39:6936-6942 
28. Russell DM, Ruamsook K, Thomchick EA. Ethanol and the petroleum supply chain of the future: Five strategic priorities of integration. Transportation Journal 2009; 48(1):5-22

29. Sokhansanj S., et. al. Large-scale production, harvest and logistics of switchgrass (Panicum virgatum L.) - current techonology and envisioning a mature technology. Biofuels, Bioprod. Bioref. 2009; 3:124-141.

30. US-DOE Energy Efficiency\&Renewable Energy, apps1.eere.energy.gov/states/transportation.cfm $/ \mathrm{state}=\mathrm{AL}$

31. Vimmerstedt L., Bush B., Peterson S. Ethanol Distribution, Dispensing, and Use: Analysis of a Portion of the Biomass-to-Biofuels Supply Chain Using System Dynamics. PlosOne 2012, 7-5, e35082

32. Wakeley H., Hendrickson C., Griffin M., Matthews S. Economic and Environmental Transportation Effects of LargeScale Ethanol Production and Distribution in the United States. Environmental Science \& Technology. 2009; 43(7):2228-2233

33. Wei L., Pordesimo L., Igathinathane C., Batchelor W. Process engineering evaluation of ethanol production from wood through bioprocessing and chemical catalysis. Biomass and Bioenergy. 2009; 33:255-266

34. You F., Grossmann I. Mixed-Integer Nonlinear Programming Models and Algorithms for Large-Scale Supply Chain Design with Stochastic Inventory Management. Ind. Eng. Chem. Res. 2008; 47 (20):7802-7817

35. You F., Wang B. Life Cycle Optmization of Biomass-to-Liquids Supply Chains with Distributed-Centralized Processing Networks. Ind. Eng. Chem. Res. 2011; 50 (17):10102-10127.

36. You F., Tao L., Graziano D.J. and Snyder S.W. Optimal design of sustainable cellulosic biofuel supply chains: Multiobjective optimization coupled with life cycle assessment and input-output analysis. AIChE Journal. 2012; 58:1157-1180. 


\section{NotATION}

\begin{tabular}{|c|c|}
\hline SETS & DESCRIPTION \\
\hline$A$ & Age of Gas Station \\
\hline$B$ & Biomass feedstock \\
\hline$D$ & Demand Zones (Gas Stations) \\
\hline$F$ & Alternative Ethanol Markets \\
\hline G & Type of Gas Stations \\
\hline $\bar{I}$ & Harvesting Sites \\
\hline$J$ & Ethanol Plants \\
\hline K & Gasoline Distribution Centers \\
\hline$L$ & Gasoline Supply \\
\hline$M$ & Transportation Modes \\
\hline$P$ & Products \\
\hline$Q$ & Technologies \\
\hline$S$ & Capacity Levels \\
\hline$T$ & Time Periods \\
\hline$T Y$ & Years \\
\hline$V$ & Retrofit Mode \\
\hline$\overline{D P I}(d, p)$ & If product $p$ is an input of retail center $d$ \\
\hline$D P O(d, p)$ & If product $p$ is an output of retail center $d$ \\
\hline$G P I(g, p)$ & If product $p$ is an input of type $g$ gas station \\
\hline$G P O(g, p)$ & If product $p$ is an output of type $g$ gas station \\
\hline$G V I(g, v)$ & If a retrofit type $v$ is done over a type $g$ gas station \\
\hline$G V O(g, v)$ & If a retrofit type $v$ generates a type $g$ gas station \\
\hline
\end{tabular}

\begin{tabular}{|c|c|c|}
\hline VARIABLE & DESCRIPTION & UNITS \\
\hline$b_{\text {bit }}$ & Biomass $b$ available in Harvesting Site $i$ in Time Period $t$ & ton $\mathrm{B} /$ per \\
\hline$c$ & Total Cost & $\$$ \\
\hline$c^{I N V}$ & Total Investment Cost & $\$$ \\
\hline$c_{d g t}^{N}$ & Gas Stations of type $g$ under construction in Retail Center $d$ In time Period $t$ & GS / per \\
\hline$c^{P R}$ & Operation and Maintenance Cost & $\$$ \\
\hline$c^{P U}$ & Gasoline purchase cost & $\$$ \\
\hline$c^{S T}$ & Storage Cost & $\$$ \\
\hline$c^{T R}$ & Transportation Cost & $\$$ \\
\hline$i l_{k p t}^{D C}$ & Inventory level of Product $p$ kept in Distribution Center $k$ in Time Period $t$ & ton $\mathrm{P} / \mathrm{repl}$ \\
\hline$i l_{j p t}^{E P}$ & Inventory level of Product $p$ kept in Ethanol Plant $j$ in Time Period $t$ & ton $\mathrm{P} / \mathrm{repl}$ \\
\hline$i_{d p t}^{G S}$ & Inventory level of Product $p$ kept in Gas Station $d$ in Time Period $t$ & ton $\mathrm{P} / \mathrm{repl}$ \\
\hline
\end{tabular}




\begin{tabular}{|c|c|c|}
\hline$n_{\text {dgta }}$ & No. of active type $g$ Gas Stations with Age $a$ in Retail Center $d$ in Time Period $t$ & GS / per \\
\hline$n_{d g t}^{r e f}$ & $\begin{array}{l}\text { No. of active type } g \text { Gas Stations in Retail Center } d \text { in Time Period } t \text { for reformulated } \\
\text { model }\end{array}$ & GS / per \\
\hline$n_{\text {dgta }}^{D}$ & $\begin{array}{l}\text { Number of dropped-off type } g \text { Gas Stations with Age } a \text { in Retail Center } d \text { in time } \\
\text { Period } t\end{array}$ & GS / per \\
\hline$n_{d g t}^{D, r e f}$ & $\begin{array}{l}\text { Number of dropped-off type } g \text { Gas Stations in Retail Center } d \text { in time Period } t \text { for } \\
\text { reformulated model }\end{array}$ & GS / per \\
\hline$n_{d g t}^{I}$ & Number of idle type $g$ Gas Stations in Retail Center $d$ in time Period $t$ & GS / per \\
\hline$n_{d g t}^{N}$ & Number of new type $g$ Gas Stations in Retail Center $d$ in time Period $t$ & GS / per \\
\hline$n_{d v t}^{R}$ & Number of type $v$ retrofitted Gas Stations in Retail Center $d$ in time Period $t$ & GS / per \\
\hline$n p c_{j q s t}^{J}$ & $\begin{array}{l}\text { New Production Capacity of Ethanol Plant } j \text { with Production Technology } q \text { of Size } s \\
\text { in Period Time } t\end{array}$ & ton Eth / per \\
\hline$n p c_{k s t}^{K}$ & $\begin{array}{l}\text { New Production Capacity of Gasoline Distribution Center } k \text { of Size } s \text { in Period Time } \\
t\end{array}$ & $\begin{array}{l}\text { ton Blend / } \\
\text { per }\end{array}$ \\
\hline$q b_{\text {bijmt }}^{I J}$ & $\begin{array}{l}\text { Flow of Biomass } b \text { from Harvesting Site } i \text { to Ethanol Plant } j \text { by Transportation Mode } \\
m \text { in Time Period } t\end{array}$ & ton $\mathrm{B} /$ per \\
\hline$q g_{k l m p t}^{L K}$ & $\begin{array}{l}\text { Flow of Gasoline from Refinery } l \text { to Distribution Center } k \text { by Transportation Mode } m \\
\text { in Time Period } t\end{array}$ & ton $\mathrm{G} /$ per \\
\hline$q p_{f j m p t}^{J F}$ & $\begin{array}{l}\text { Flow of Product } p \text { from Ethanol Plant } j \text { to Alternative Ethanol Markets } f \text { by } \\
\text { Transportation Mode } m \text { in Time Period } t\end{array}$ & ton $\mathrm{P} /$ per \\
\hline$q p_{j k m p t}^{J K}$ & $\begin{array}{l}\text { Flow of Product } p \text { from Ethanol Plant } j \text { to Distribution Center } k \text { by Transportation } \\
\text { Mode } m \text { in Time Period } t\end{array}$ & ton $\mathrm{P} /$ per \\
\hline$q p_{d k m p t}^{K D}$ & $\begin{array}{l}\text { Flow of Product } p \text { from Distribution Center } k \text { to Retail Center } d \text { by Transportation } \\
\text { Mode } m \text { in Time Period } t\end{array}$ & ton $\mathrm{P} /$ per \\
\hline sales $_{d p t}$ & Sales of Product $p$ within Retail Center $d$ in Time Period $t$ & ton $\mathrm{P} /$ per \\
\hline$s b_{b j t}^{J}$ & Storage of Biomass $b$ in Ethanol Plant $j$ in Time Period $t$ & ton $\mathrm{B} /$ per \\
\hline$s p_{d p t}^{D}$ & Storage of Product $p$ in Retail Center $d$ in Time Period $t$ & ton $\mathrm{P} /$ per \\
\hline$s p_{j p t}^{J}$ & Storage of Product $p$ in Ethanol Plant $j$ in Time Period $t$ & ton $\mathrm{P} /$ per \\
\hline$s p_{k p t}^{K}$ & Storage of Product $p$ in Distribution Center $k$ in Time Period $t$ & ton $\mathrm{P} /$ per \\
\hline$t i c_{k t}^{D C}$ & Total Capital Investment Cost in Distribution Center $k$ in Time Period $t$ & $\$$ \\
\hline$t i c_{j t}^{E P}$ & Total Capital Investment Cost in Ethanol Plant $j$ in Time Period $t$ & $\$$ \\
\hline$t i c_{d t}^{G S}$ & Total Capital Investment Cost within Retail Center $d$ in Time Period $t$ & $\$$ \\
\hline$t i c_{i t}^{H S}$ & Total Capital Investment Cost in Harvesting Site $i$ in Time Period $t$ & $\$$ \\
\hline$w_{\text {bjqt }}^{I-B}$ & $\begin{array}{l}\text { Amount of Biomass } b \text { consumed in Ethanol Plant } j \text { of Production Technology } q \\
\text { within Time Period } t\end{array}$ & ton $\mathrm{B} /$ per \\
\hline$w_{d p p^{\prime} p^{\prime \prime} t}^{I-D}$ & $\begin{array}{l}\text { Amount of Product } p^{\prime} \text { mixed with Product } p^{\prime \prime} \text { to produce Product } p \text { within Retail } \\
\text { Center } d \text { in Time Period } t\end{array}$ & ton $\mathrm{P}^{\prime} /$ per \\
\hline$w_{j p q t}^{I-J}$ & $\begin{array}{l}\text { Amount of Product } p \text { consumed in Ethanol Plant } j \text { of Production Technology } q \text { within } \\
\text { Time Period } t\end{array}$ & ton $\mathrm{P} /$ per \\
\hline$w_{\text {kpp'p } p^{\prime \prime} q t}^{I-K}$ & $\begin{array}{l}\text { Amount of Product } p^{\prime} \text { mixed with Product } p^{\prime \prime} \text { to produce Product } p \text { with mixing } \\
\text { Technology } q \text { in Distribution Center } k \text { in Time Period } t\end{array}$ & ton $\mathrm{P}^{\prime} /$ per \\
\hline$w_{d p t}^{O-D}$ & Amount of Product $p$ produced in Retail Center $d$ in Time Period $t$ & ton $\mathrm{P} /$ per \\
\hline$w_{j p q t}^{O-J}$ & $\begin{array}{l}\text { Amount of Product } p \text { produced in Ethanol Plant } j \text { with Production Technology } q \text { in } \\
\text { Time Period } t\end{array}$ & ton $\mathrm{P} /$ per \\
\hline$w_{k p t}^{O-K}$ & Amount of Product $p$ produced in Distribution Center $k$ in Time Period $t$ & ton $\mathrm{P} /$ per \\
\hline
\end{tabular}




\begin{tabular}{|l|l|l|}
\hline$y_{b i t}^{I}$ & Whether Biomass $b$ is sown in Harvesting Site $i$ in Time Period $t$ or not & \\
\hline$y_{b i}^{I-M P}$ & Whether Biomass $b$ is sown in Harvesting Site $i$ or not for MP model & \\
\hline$y_{j q s t}^{J}$ & $\begin{array}{l}\text { Whether Ethanol Plant } j \text { with Production Technology } q \text { and Size } s \text { is installed in Time } \\
\text { Period } t \text { or not }\end{array}$ & \\
\hline$y_{j q}^{J-M P}$ & $\begin{array}{l}\text { Whether Ethanol Plant } j \text { with Production Technology } q \text { is installed or not for MP } \\
\text { model }\end{array}$ & \\
\hline$y_{k s t}^{K}$ & Whether Distribution Center $k$ of Size $s$ is installed in Time Period $t$ or not & \\
\hline$y_{k}^{K-M P}$ & Whether Distribution Center $k$ is installed or not for MP model & \\
\hline
\end{tabular}

\begin{tabular}{|c|c|c|}
\hline PARAMETER & DESCRIPTION & UNITS \\
\hline$\alpha_{k t}^{D C}$ & $\begin{array}{l}\text { Fixed Production Cost in Distribution Center } k \text { in Time Period } t \text { as a percentage of } \\
\text { Investments }\end{array}$ & $\%$ \\
\hline$\alpha_{j t}^{E P}$ & $\begin{array}{l}\text { Fixed Production Cost in Ethanol Plant } j \text { in Time Period } t \text { as a percentage of } \\
\text { Investments }\end{array}$ & $\%$ \\
\hline$\alpha_{d t}^{G S}$ & $\begin{array}{l}\text { Fixed Production Cost in Retail Center } k \text { in Time Period } t \text { as a percentage of } \\
\text { Investments }\end{array}$ & $\%$ \\
\hline$\alpha_{i t}^{H S}$ & $\begin{array}{l}\text { Fixed Production Cost in Harvesting Sites } i \text { in Time Period } t \text { as a percentage of } \\
\text { Investments }\end{array}$ & $\%$ \\
\hline$\beta_{j}$ & Percentage of ethanol in Ethanol Plant $j$ destinated to consumption of other industries & $\%$ \\
\hline$\lambda_{\text {MAX }}$ & Factor to estimate the maximal storage capacity to handle the needed inventory & $\%$ \\
\hline$\lambda_{\text {MIN }}$ & $\begin{array}{l}\text { Factor to estimate the minimal storage capacity required to handle the needed } \\
\text { inventory }\end{array}$ & $\%$ \\
\hline$\mu_{p p^{\prime} p^{\prime \prime}}^{B}$ & Amount of Product $p^{\prime}$ needed to produce $p$ in a mix with $p^{\prime \prime}$ & $\begin{array}{l}\text { ton } \mathrm{P} / \text { ton } \\
\mathrm{P}\end{array}$ \\
\hline$\mu_{b q}^{P}$ & Yield of ethanol to biomass $b$ associated to Production Technology $q$ & $\begin{array}{l}\text { ton E100/ } \\
\text { ton B }\end{array}$ \\
\hline$\theta_{j q}^{J}$ & $\begin{array}{l}\text { Minimal percentage of production allowed in Ethanol Plant } j \text { with Production } \\
\text { Technology } q\end{array}$ & $\%$ \\
\hline$A B_{\text {bit }}$ & Amount of Available Biomass $b$ in Harvesting Site $i$ in Time Period $t$ & ton $\mathrm{B} /$ per \\
\hline$C G_{l t}$ & Cost of Gasoline in Refinery $l$ in Time Period $t$ & $\$ /$ ton $\mathrm{G}$ \\
\hline$D_{d k m}^{D K}$ & $\begin{array}{l}\text { Distance between Distribution Center } k \text { and Retail Center } d \text { by Transportation Mode } \\
m\end{array}$ & $\mathrm{~km}$ \\
\hline$D_{f j m}^{F J}$ & Distance between Ethanol Plant $j$ and Alternative Market $f$ by Transportation Mode $m$ & $\mathrm{~km}$ \\
\hline$D_{i j m}^{I J}$ & Distance between Harvesting Site $i$ and Ethanol Plant $j$ by Transportation Mode $m$ & $\mathrm{~km}$ \\
\hline$D_{j k m}^{J K}$ & $\begin{array}{l}\text { Distance between Ethanol Plant } j \text { and Distribution Center } k \text { by Transportation Mode } \\
m\end{array}$ & $\mathrm{~km}$ \\
\hline$D_{k l m}^{K L}$ & Distance between Refinery $l$ and Distribution Center $k$ by Transportation Mode $m$ & $\mathrm{~km}$ \\
\hline$D E M_{d t}$ & Demand of Fuel in Retail Center $d$ in Time Period $t$ & ton / per \\
\hline$E P C_{j q}^{J}$ & Existing Production Capacity of Ethanol Plant $j$ with Production Technology $q$ & $\begin{array}{l}\text { ton Eth } / \\
\text { per }\end{array}$ \\
\hline$E P C_{k}^{K}$ & Existing Production Capacity of Distribution Center $k$ & $\begin{array}{l}\text { ton Blend / } \\
\text { per }\end{array}$ \\
\hline$F C N_{d g}$ & Fixed Capital Investment for new type $g$ Gas Stations within Retail Center $d$ & $\$ / G S$ \\
\hline$F C R_{d v}$ & Fixed Capital Investment for type $v$ retrofits within Retail Center $d$ & $\$ / G S$ \\
\hline$F I C_{k s}^{D C}$ & Fixed Investment Cost on Distribution Center $k$ of Size $s$ & $\$$ \\
\hline$F I C_{j q s}^{E P}$ & Fixed Investment Cost on Ethanol Plant $j$ with Production Technology $q$ of Size $s$ & $\$$ \\
\hline
\end{tabular}




\begin{tabular}{|c|c|c|}
\hline$F I C_{i}^{H S}$ & Fixed Investment Cost on Harvesting Site $i$ & $\$$ \\
\hline$F T C_{b m t}^{B}$ & Fixed Transportation Cost of Biomass $b$ by Transportation Mode $m$ in Time Period $t$ & $\$ /$ ton $\mathrm{B}$ \\
\hline$F T C_{p m t}^{P}$ & Fixed Transportation Cost of Product $p$ by Transportation Mode $m$ in Time Period $t$ & $\$ /$ ton $\mathrm{P}$ \\
\hline$L B P C_{j q}^{E P}$ & $\begin{array}{l}\text { Lower Bound on Production Capacity of Ethanol Plant } j \text { with Production Technology } \\
q\end{array}$ & $\begin{array}{l}\text { ton Eth / } \\
\text { per }\end{array}$ \\
\hline$L B P C_{k}^{D C}$ & Lower Bound on Production Capacity of Distribution Center $k$ & $\begin{array}{l}\text { ton Blend / } \\
\text { repl }\end{array}$ \\
\hline NINIT $_{\text {dga }}$ & Amount of type $g$ existing Gas Stations with Age $a$ within Retail Center d & No GS \\
\hline$N J_{q s t}$ & Max number of ethanol plants per Production Technology $q$, Size $s$ and year $t$ & $\begin{array}{ll}\text { No } & \text { Eth } \\
\text { Plants }\end{array}$ \\
\hline$N J_{j t}^{T O T}$ & Max number of ethanol plants per year $t$ and per potential location $j$ & $\begin{array}{ll}\text { No } & \text { Eth } \\
\text { Plants }\end{array}$ \\
\hline$N K_{\text {st }}$ & Max number of distribution centers per size $s$ and year $t$ & No DC \\
\hline$N K_{k t}^{T O T}$ & Max number of distribution centers per year $t$ and per potential location $k$ & No DC \\
\hline$P B_{p}$ & Percentage of Fuel Demand corresponding to Product $p$ & $\%$ \\
\hline$P C_{k s}^{D C}$ & Production Capacity of Distribution Center $k$ and Size $s$ & $\begin{array}{l}\text { ton Blend / } \\
\text { repl }\end{array}$ \\
\hline$P C_{j q s}^{E P}$ & Production Capacity of Ethanol Plant $j$ with Production Technology $q$ and Size $s$ & $\begin{array}{l}\text { ton Eth / } \\
\text { per }\end{array}$ \\
\hline$P C_{d g}^{D}$ & Production Capacity of type $g$ Gas Stations within Retail Center $d$ & $\begin{array}{l}\text { ton Blend / } \\
\text { GS }\end{array}$ \\
\hline$P T O_{d g t}^{G}$ & $\begin{array}{l}\text { Proportional Time of Construction of type } g \text { new Gas Stations within Retail Center } d \\
\text { in Time Period } t\end{array}$ & Idle $\mathrm{hr} / \mathrm{hr}$ \\
\hline$P T O_{d v t}^{V}$ & $\begin{array}{l}\text { Proportional Time of Construction of type } v \text { retrofitted Gas Stations within Retail } \\
\text { Center } d \text { in Time Period } t\end{array}$ & Idle $\mathrm{hr} / \mathrm{hr}$ \\
\hline$S C_{b j t}^{B J}$ & Storage Capacity of Biomass $b$ in Ethanol Plant $j$ in Time Period $t$ & ton $\mathrm{B} /$ per \\
\hline$S C_{d g p}^{M A X}$ & $\begin{array}{l}\text { Maximal Capacity of the underground tanks that stored Product } p \text { in type } g \text { Gas } \\
\text { Stations within Retail Center } d\end{array}$ & ton $\mathrm{P} /$ per \\
\hline$S C_{d g p}^{M I N}$ & $\begin{array}{l}\text { Minimal Capacity of the underground tanks that stored Product } p \text { in type } g \text { Gas } \\
\text { Stations within Retail Center } d\end{array}$ & ton $\mathrm{P} /$ per \\
\hline$S C_{d p t}^{P D}$ & Storage Capacity of Product $p$ in Retail Center $d$ in Time Period $t$ & ton $\mathrm{P} /$ per \\
\hline$S C_{j p t}^{P J}$ & Storage Capacity of Product $p$ in Ethanol Plant $j$ in Time Period $t$ & ton $\mathrm{P} /$ per \\
\hline$S C_{k p t}^{P K}$ & Storage Capacity of Product $p$ in Distribution Center $k$ in Time Period $t$ & ton $\mathrm{P} /$ per \\
\hline$T O R_{d t}^{D}$ & Turnover Ratio of Retail Center $d$ within time Period $t$ & days / repl \\
\hline$T O R_{j t}^{J}$ & Turnover Ratio of Ethanol Plant $j$ within time Period $t$ & repl / per \\
\hline$T O R_{k t}^{K}$ & Turnover Ratio of Distribution Center $k$ within time Period $t$ & repl / per \\
\hline$V I C_{i}^{H S}$ & Variable Investment Cost on Harvesting Site $i$ & $\$ /$ ton $\mathrm{B}$ \\
\hline$V P C_{d p t}^{D}$ & Variable Production Cost of Product $p$ in Retail Center $d$ in Time Period $t$ & $\$ /$ ton $\mathrm{P}$ \\
\hline$V P C_{b i t}^{I}$ & Variable Production Cost of Biomass $b$ in Harvesting Site $i$ in Time Period $t$ & $\$ /$ ton $\mathrm{B}$ \\
\hline$V P C_{j q t}^{J}$ & $\begin{array}{l}\text { Variable Production Cost in Ethanol Plant } j \text { with Production Technology } q \text { in Time } \\
\text { Period } t\end{array}$ & $\$ /$ ton E85 \\
\hline$V P C_{k t}^{K}$ & Variable Production Cost in Distribution Center $k$ in Time Period $t$ & $\begin{array}{l}\$ 1 \text { ton } \\
\text { blend }\end{array}$ \\
\hline
\end{tabular}




\begin{tabular}{|l|l|l|}
\hline$V T C_{b m t}^{B}$ & $\begin{array}{l}\text { Variable Transportation Cost of Biomass } b \text { by Mode of Transportation } m \text { in Time } \\
\text { Period } t\end{array}$ & $\begin{array}{l}\$ / \text { ton } \\
\text { B.km }\end{array}$ \\
\hline$V T C_{p m t}^{P}$ & $\begin{array}{l}\text { Variable Transportation Cost of Product } p \text { by Mode of Transportation } m \text { in Time } \\
\text { Period } t\end{array}$ & $\begin{array}{l}\$ / \text { ton } \\
\text { P.km }\end{array}$ \\
\hline$W C_{i m t}$ & Weight Capacity of Transportation Mode $m$ from Harvesting Site $i$ in Time Period $t$ & ton B / per \\
\hline
\end{tabular}




\title{
SUPPLEMENTARY MATERIAL TO
}

\section{Multiscale Strategic Planning Model for the Design of Integrated Ethanol and Gasoline Supply Chain}

\author{
Andersen F. ${ }^{1,2}$, Díaz M.S. ${ }^{1}$, Grossmann I.E. ${ }^{2}$ \\ ${ }^{1}$ Planta Piloto de Ingeniería Química, PLAPIQUI, Universidad Nacional del Sur, \\ CONICET. Camino La Carrindanga km 7, 8000 Bahía Blanca, ARGENTINA \\ ${ }^{2}$ Department of Chemical Engineering, Carnegie Mellon University, Pittsburgh PA 15213, US
}

\section{Decomposition Algorithm}

Due to the multiscale nature of the model for the design of the integrated supply chain of gasoline and ethanol, we have developed a bilevel decomposition algorithm where the upper level problem makes the long-term decisions and the lower level one performs the short-term decisions, including information on retrofits over gas stations. The decomposition algorithm is based on the one presented by Iyer and Grossmann (1998), where the upper level problem is solved to decide the selection of processes over the entire time horizon, and in the lower level the problem is solved for the selected set of processes. We have extended this problem to the multisite and multimarket case, because we have addressed the shipments between potential production sites and retail centers through the supply chain model (Dogan and Grossmann, 2006; Terrazas-Moreno and Grossmann, 2011)

According to the flowchart in Fig. 1, the proposed decomposition algorithm solves a higher level problem (MP master problem) where the decisions taken are related to the selection of processes in each location, regardless of size and year; and are also related to the sales of fuel blends in every retail center, regardless of the number of gas stations required to comply with these sales. The higher level problem is a relaxation of the original problem $(\mathrm{P})$, and therefore its solution provides a lower bound to the cost.

After solving the MP, a lower level problem (SP - subproblem) is solved for the optimal processes selected in the master problem, and with tighter bounds on the integer variables that represent the number of gas stations. These bounds also come from the solution of the master problem. As this lower level problem is solved for the selected processes in the higher level problem, the feasible region is included within the feasible region of the original model $\mathrm{P}$, and therefore it yields an upper bound on the objective function. The solution of the problem is obtained by solving iteratively MP and SP problems according to the flowchart on Fig. 1 until convergence is achieved within a specified tolerance. Computational results show that reductions of the order of $40 \%$ can be achieved. 


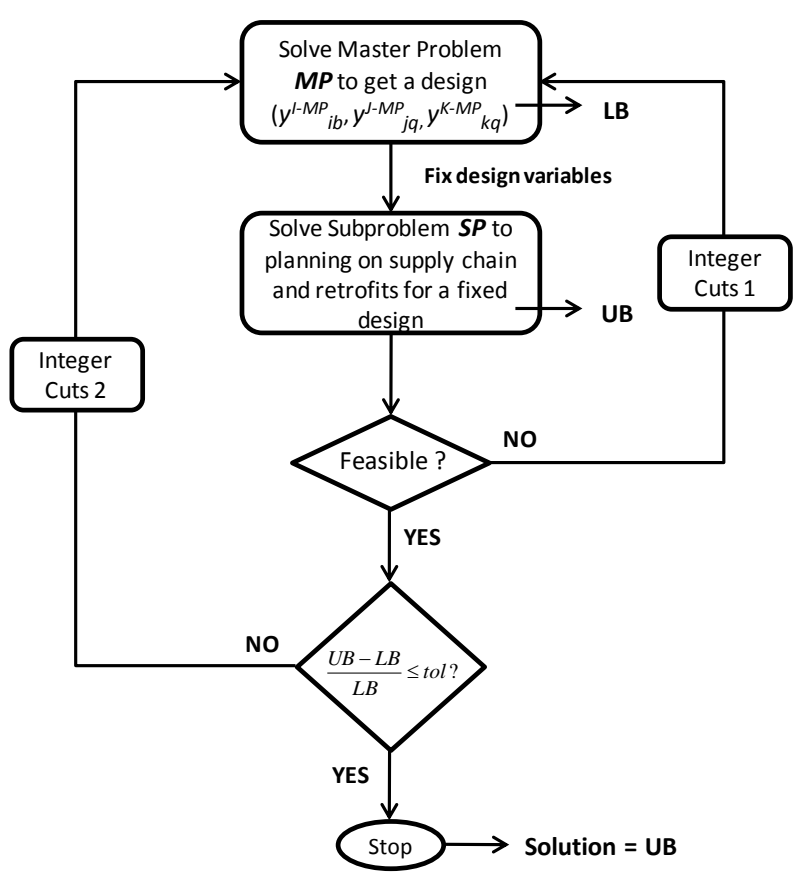

Fig. 1. Flowchart for the bilevel decomposition algorithm

\subsection{Higher Level Problem - MP}

The main idea in this part of the decomposition algorithm is to address higher level decisions and simplify other parts of the model as was explained at the beginning of this section. The major decisions are as follows:

1- Aggregate binary variables to represent the selection of processes over the entire time horizon in each location, simplifying the dimensions of size and time of the investments. $\left(y_{b i}^{I-M P}, y_{j q}^{J-M P}, y^{K-M P}\right)$.

2- Consider all the integer variables associated to the number of gas stations as continuous variables.

3- Consider an alternative formulation for the dynamic set of gas stations- Eqs (48) and (49)

The reasons for these approximations are not only to reduce the number of binary variables, and in that way decrease the combinatorial complexity of the problem, but also to reduce the number of integer variables to obtain a faster solution of the master problem. Items 2 and 3 are related to the formulation of gas stations in different ways. The second one considers a relaxation of all integer variables, and the third one considers a reformulation to achieve a smaller representation. As these items refer to modifications on the same part of the model (retail centers), only one of them can be applied in MP model at the same time. We address only the third issue, because it considers integer variables for the representation of gas stations even though the reformulation is applied.

The reformulation is presented in subsection 1.1.1. :

\subsubsection{Reformulation of gas stations equations}

Approximately $40 \%$ of the variables $(96,480$ out of 233,475$)$ correspond to the formulation of dynamic sets of gas stations. If we are able to simplify this formulation, the entire problem will be easier to solve. 
Consider the general scheme represented in Fig. 5 (or LHS of Fig. 2). A pattern that repeats over the dimension of age of gas stations can be identified. Therefore, the dimension of age can be eliminated to obtain another representation of the same behavior with the inclusion of additional equations. Graphically, the LHS of Fig. 2 can be transformed into its RHS.
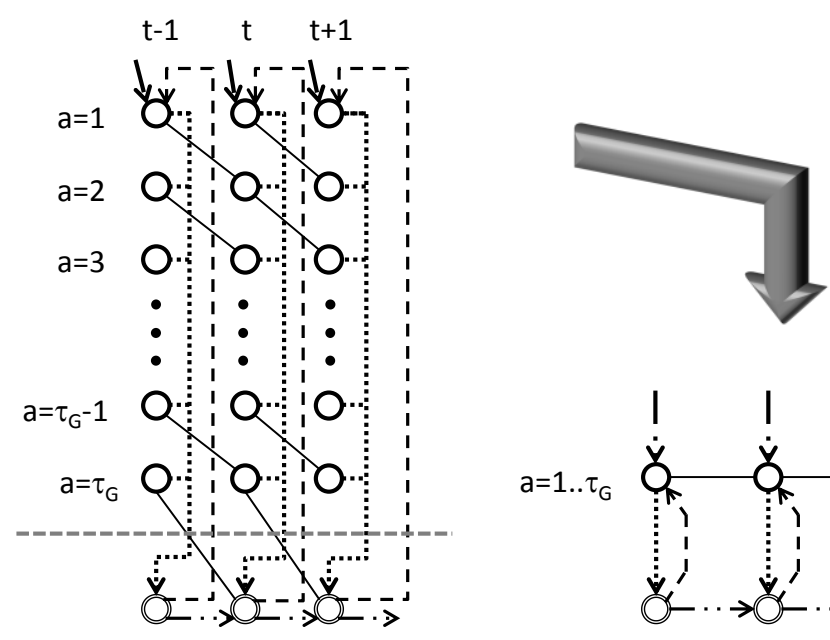

Fig. 2. Simplification for modeling the behavior of gas stations

This projection eliminates age index for each gas station and Eqs (39) and (40) can be re-written without the age subscript as Eqs. (59) and (60), which are simple inventory balances of the RHS of Fig 2.

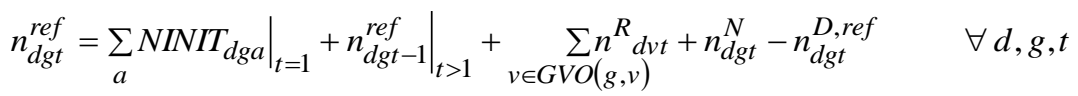

$$
n_{d g t}^{I}=\left.n_{d g t-1}^{I}\right|_{t>1}+n_{d g t}^{D, r e f}-\sum_{v \in G V I(g, v)}^{n_{d v t}^{R}} \quad \forall d, g, t
$$

Since aging is no longer included in the previous equations, the mandatory retrofits after $\tau_{\mathrm{G}}$ years of continuous operation are not included either. In the conversion of the LHS into the RHS of Fig. 2, it can be seen that the arrows that connect the circle of active gas stations of age $\tau_{\mathrm{G}}$ with the circle of idle gas stations (solid line arrows) are no longer represented. This means that the required number of gas stations that must be eliminated because their lifetime is over is not clearly represented in the RHS of Fig. 2.

An overall balance on the number of gas stations from year $t-\tau_{\mathrm{G}}$ to year $t$ can be formulated. The goal of this balance is to impose a minimum number on the dropped-off gas stations $\left(n_{d g t}^{D}\right)$, which might be equal to the number of gas stations that must be retrofitted to keep working. This feature is stated in Eq. (61).

$$
n_{d g t}^{D, r e f} \geq \sum_{a \geq \tau_{G}+1-t} N_{I N I T} T_{d g a}+n_{d g t-\tau_{G}}^{r e f}-\sum_{t-\tau_{G}<t^{\prime} \leq t} n_{d g t^{\prime}}^{D, r e f} \quad \forall d, g, t
$$


In this equation, the number of gas stations that must be dropped-off according to their age is given by the number of gas stations that were active $\tau_{G}$ years ago $\left(n_{d g t-\tau_{G}}^{r e f}\right)$ minus the summation over all dropped-off gas stations since $\tau_{G}$ years up to the current year $\left(\sum_{t-\tau_{G}<t^{\prime} \leq t} n_{d g t^{\prime}}^{D, r e f}\right)$. It is clear that when the current year is lower than $\tau_{G}$, the set of initial gas stations must be considered in this calculation.

In this formulation (Eqs. 59 to 61), it is assumed that the gas stations are being dropped-off according to their age. In the first place the older ones, and later the younger ones. In the previous formulation, theoretically, some younger gas stations can be dropped-off while the older ones keep working. However, because the older ones have not only a shorter remaining lifetime but also larger operation and maintenance costs, it is more convenient to drop off the oldest gas stations in the first place. Consequently, the formulations are equivalent.

Finally, the higher level problem is defined as follows:

\subsubsection{Higher Level Problem with Reformulation - MP}

The description of most equations is omitted here, because it is provided in the description of the general model P.

In this subsection we list all the equations included in MP, writing only those that are modified with respect to the original problem $\mathrm{P}$.

\section{Equations}

Then, the higher level problem with the reformulation of the retail centers part is defined by:

$\mathrm{MP}: \quad \min c=c^{I N V}+c^{P R}+c^{T R}+c^{S T}+c^{P U}$

subject to:

The equations on Harvesting Sites with the simplification of binary variables.

- Eq. 1

- $\quad b h s_{b i t} \leq A B_{b i t} y_{b i}^{I-M P} \quad \forall b, i, t$

The equations on Ethanol Plants with the simplification of binary variables.

- $\quad$ Eq 3-11

- $\quad n p c_{j q s t}^{J} \leq P C_{j q s}^{E P} y_{j q}^{J-M P} \quad \forall j, q, s, t$

- $\quad$ Eq. 15 
- $\sum_{q} y_{j q}^{J-M P} \leq \frac{\sum_{t} N J_{j t}^{T O T}}{\operatorname{card}(s) \operatorname{card}(t)} \quad \forall j$

- $\sum_{j} y_{j q}^{J-M P} \leq \frac{\sum_{t} \sum_{s} N J_{q s t}}{\operatorname{card}(s) \operatorname{card}(t)} \quad \forall q$

The derivation of equations 64 and 65 is provided in Appendix A.

The equations on Distribution Centers with the simplification of binary variables.

- Eqs. $18-24$

- $\quad n p c_{k s t}^{K} \leq P C_{k s}^{D C} y_{k}^{K-M P} \quad \forall k, q, s, t$

- Eq. 27

- $y_{k}^{K-M P} \leq \frac{\sum_{t} N K_{k t}^{T O T}}{\operatorname{card}(s) \operatorname{card}(t)} \quad \forall k$

- $\sum_{k} y_{k}^{K-M P} \leq \frac{\sum_{t} \sum_{s} N K_{s t}}{\operatorname{card}(s) \operatorname{card}(t)}$

The derivation of equations 67 and 68 is also provided in Appendix A.

The equations on Retail Centers with the reformulation of gas stations modeling:

- Eqs. $30-38$

The inventory level is re-written in Eqs. (69) and (70):.

- $\quad i l_{d p t}^{G S} \leq \sum_{g \in G P I(g, p)} S C_{d g p}^{M A X} n_{d g t}^{r e f} \forall d, p \in \operatorname{DPI}(d, p), t$

- $\quad i l_{d p t}^{G S} \geq \sum_{g \in G P I(g, p)} S C_{d g p}^{M I N} n_{d g t}^{r e f} \forall d, p \in \operatorname{DPI}(d, p), t$

The reformulation of gas station balance as is described above is represented by:

- Eqs. $59-61$

The next equations represent upper and lower bounds in the amount of fuel that gas stations can provide. 
- $\left.\quad w_{d p t}^{O-D} \leq \sum_{g \in G P O(g, p)} P C_{d g}^{D} \mid n_{d g t}^{r e f}-c_{d g t}^{N}\right\rfloor \quad \forall d p=\{E 10 ; E 30 ; E 85\} t$

- $\left.w_{d p t}^{O-D}+w_{d p^{\prime} t}^{O-D} \leq \sum_{g \in \vee} \sum_{G P O(g, p)} P C_{d g}^{D}\left|n_{d g t}^{r e f}-c_{d g t}^{N}\right| \quad \forall d\left\{p, p^{\prime}\right\}=\{\{E 10, E 30\} ;\{E 10, E 85\} ;\{E 30, E 85\}\}\right\} t$

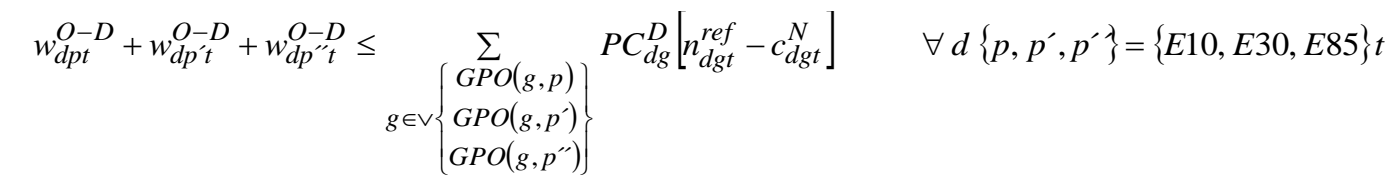

- Eq. 46

- $w_{d p p p t}^{I-D} \geq 0.50 P C_{d g}^{D} n_{d g t}^{r e f} \quad \forall d\{p, g\}=\{\{E 10, G 1\},\{E 30, G 2\}\} t$

- $\quad w_{d E 10 p p^{\prime} t}^{I-D}+w_{d E 30 p p^{\prime} t}^{I-D}+w_{d E 85 p p^{\prime} t}^{I-D} \geq 0.50 P C_{d^{\prime} G 3^{\prime}}^{D} n_{d^{\prime} G 3^{\prime} t}^{r e f} \quad \forall d\left\{p, p^{\prime}\right\}=\{E 10, E 85\} t$

The equations in the Objective Function are:

- $\quad$ Eq 49

- $\quad t i c_{i t}^{H S}=\sum_{b} F I C_{i}^{H S}\left(\frac{b h s_{b i t}}{A B_{b i t}}\right)+V I C_{i}^{H S} b h s_{b i t} \quad \forall i t$

- $t i c_{j t}^{E P}=\sum_{q} \sum_{s}\left[F I C_{j q s-1}^{E P}\left(\frac{n p c_{j q s t}^{J}}{P C_{j q s}^{E P}}\right)+\left(n p c_{j q s t}^{J}-P C_{j q s-1}^{E P}\left(\frac{n p c_{j q s t}^{J}}{P C_{j q s}^{E P}}\right)\right) \frac{F I C_{j q s}^{E P}-F I C_{j q s-1}^{E P}}{P C_{j q s}^{E P}-P C_{j q s-1}^{E P}}\right] \quad \forall j t$

- $t i c_{k t}^{D C}=\sum_{s}\left[F I C_{k s-1}^{D C}\left(\frac{n p c_{k s t}^{K}}{P C_{k s}^{D C}}\right)+\left(n p c_{k s t}^{K}-P C_{k s-1}^{D C}\left(\frac{n p c_{k s t}^{K}}{P C_{k s}^{D C}}\right)\right) \frac{F I C_{k s}^{D C}-F I C_{k s-1}^{D C}}{P C_{k s}^{D C}-P C_{k s-1}^{D C}}\right] \quad \forall k t$

- Eqs. $53-57$

In Eqs. (76), (77) and (78) the binary variables were replaced by the underestimation obtained from Eqs. (62), (63) and (66).

The equations are displayed in the same order as in problem P definition. 


\section{Integer Cuts}

Integer cuts are added at each iteration (from iteration 2 onwards) in order to incorporate information provided in previous MP models and the last SP model.

Eq. (79) is used to exclude previous feasible solutions. Eqs. (80) to (85) are integer cuts to preclude solutions that are already known as suboptimal alternatives, based on the information obtained in previous higher level problem. These cuts were developed and presented by Iyer and Grossmann (1998). Eq. (86) sets a lower bound on the number of gas stations, using the optimal solution obtained in the previous higher level problem (MP). The reason for this equation is to assure an amount of petrol stations that can satisfy the demand, at least in the same way as in the previous iteration.

$$
\begin{aligned}
& \left\{\begin{aligned}
& {\left[\sum_{(b, i) \in Z_{1}^{I, r}} y_{b i}^{I-M P}+\sum_{(j, q) \in Z_{1}^{J, r}} y_{j q}^{J-M P}+\sum_{\mathrm{k} \in Z_{1}^{K, r}} y_{k}^{K-M P}\right)-} \\
& \left.\left(\sum_{(b, i) \in Z_{0}^{I, r}} y_{b i}^{I-M P}+\sum_{(j, q) \in Z_{0}^{J, r}} y_{j q}^{J-M P}+\sum_{\mathrm{k} \in Z_{0}^{K, r}} y_{k}^{K-M P}\right)\right] \leq\left(Z_{1}^{I, r}+Z_{1}^{J, r}+Z_{1}^{K, r}\right)-1 \quad \forall r<R
\end{aligned}\right. \\
& \left(\sum_{\left(b^{\prime}, i^{\prime}\right) \in Z_{1}^{I, r}} y_{b^{\prime} i^{\prime}}^{I-M P}+y_{b i}^{I-M P} \leq\left|Z_{1}^{I, r}\right| \quad \forall(b, i) \in Z_{0}^{I, r} r<R\right. \\
& \sum_{\left(j^{\prime}, q^{\prime}\right) \in Z_{1}^{J, r}} y_{j^{\prime} q^{\prime}}^{J-M P}+y_{j q}^{J-M P} \leq\left|Z_{1}^{J, r}\right| \quad \forall(j, q) \in Z_{0}^{J, r} r<R \\
& \sum_{k^{\prime} \in Z_{1}^{K, r}} y_{k^{\prime}}^{K-M P}+y_{k}^{K-M P} \leq\left|Z_{1}^{K, r}\right| \quad \forall k \in Z_{0}^{K, r} r<R \\
& \sum_{\left(b^{\prime}, i^{\prime}\right) \in Z_{0}^{I, r}} y_{b^{-} i^{\prime}}^{I-M P}+y_{b i}^{I-M P} \geq 1 \quad \forall(b, i) \in Z_{1}^{I, r} r<R \\
& \sum_{\left(j^{\prime}, q^{\prime}\right) \in Z_{0}^{J, r}} y_{j^{\prime} q^{\prime}}^{J-M P}+y_{j q}^{J-M P} \geq 1 \quad \forall(j, q) \in Z_{1}^{J, r} r<R \\
& \sum_{k^{\prime} \in Z_{0}^{K, r}} y_{k^{\prime}}^{K-M P}+y_{k}^{K-M P} \geq 1 \quad \forall k \in Z_{1}^{K, r} r<R \\
& \left\{\sum_{g} n_{d g t}^{r e f} \geq \sum_{g} \overline{n_{d g t}^{r e f}} r \quad \forall d t \quad r=R-1\right.
\end{aligned}
$$

Where

$$
\begin{aligned}
& Z_{1}^{I, r}=\left\{b, i \mid \bar{y}_{b i}^{I-M P, r}=1\right\} ; Z_{0}^{I, r}=\left\{b, i \mid \bar{y}_{b i}^{I-M P, r}=0\right\} ; Z_{1}^{J, r}=\left\{j, q \mid \bar{y}_{j q}^{J-M P, r}=1\right\} ; \\
& Z_{0}^{J, r}=\left\{j, q \mid \bar{y}_{j q}^{J-M P, r}=0\right\} ; Z_{1}^{K, r}=\left\{k \mid \bar{y}_{k}^{K-M P, r}=1\right\} ; Z_{0}^{K, r}=\left\{k \mid \bar{y}_{k}^{K-M P, r}=0\right\}
\end{aligned}
$$




\section{Main Changes}

Summarizing, the changes in the model with respect to $\mathrm{P}$ are as follows:

a. Objective function: eq. (50) is replaced by (76); (51) by (77); (52) by (78).

b. Upper bound on capacity: eq. (2) is replaced by (62); (12) and (13) by (63); (25) and (26) by (66).

Changes in the objective function have been implemented through the investment cost (Eqs. 76 to 78); with the replacement of binary variables according to the new equations for the upper bound on capacity (Eqs. 62; 63 and 66). Investment costs have been underestimated since:

$$
\begin{gathered}
\frac{b h s_{b i t}}{A B_{b i t}} \leq y_{b i}^{I-M P} \quad \forall \text { bit } \\
\frac{n p c_{j q s t}^{J}}{P C_{j q s}^{E P}} \leq y_{j q}^{J-M P} \quad \forall j q s t \\
\frac{n p c_{k s t}^{K} / T O R_{k t}^{K}}{P C_{k s}^{D C}} \leq y_{k}^{K-M P} \quad \forall k s t
\end{gathered}
$$

And because of the minimization direction of the optimization problem, the objective function is also underestimated.

c. Logic Cuts: eq. (16) is replaced by (64); (17) by (65); (28) by (67); (29) by (68).

d. Lower bounds on Production: eq. (14) is eliminated

Items $c$ and $d$ involve the elimination of the lower bounds of production and the projection of the logic cuts into the new dimensions of the problem (fewer than before). These features lead to a relaxation of the problem.

e. Retail centers: eq. (41) is replaced by (69); (42) by (70); eqs. (39) and (40) by eqs. (59) - (61); eqs. (43) to (45) by (71) to (73); eqs. (47) and (48) by (74) and (75).

f. Integer cuts: Adding integer cuts to reduce the feasible space. Eqs. (79) to (86).

Integer cuts reduce the search space taking into account information of previous iterations. Iyer and Grossmann (1998) prove that these integer cuts do not exclude better solutions.

Finally, because of the underestimation of the objective function and the relaxation of the problem, the solution of this model yields a lower bound on the solution of general problem $\mathrm{P}$. 


\subsection{Lower Level Problem - SP}

In this subsection we list all the equations included in SP, writing only those that are modified with respect to the original problem $\mathrm{P}$.

The description of most equations is also omitted here, because it is provided in the description of the general model P. The point in this problem is to solve the model $\mathrm{P}$ addressing information about the solution of previous models to limit the search space. The processes not selected in MP are excluded with Eqs (87) - (89) and the number of gas stations that can be installed are cut down according to the solution of previous MP, with Eq. (90). In this way, the main objective is to solve a problem like $\mathrm{P}$ but in a lower time due to a reduction of the feasible region due to these cuts.

\section{Equations}

Therefore, the lower level problem (SP) is defined by:

$\mathrm{SP}: \quad \min c=c^{I N V}+c^{P R}+c^{T R}+c^{S T}+c^{P U}$

subject to:

- Eqs. (1) - (57).

We can note that problem SP is similar to problem P (it has the same equations), but with the addition of integer cuts in Eqs (87) - (90).

\section{Integer Cuts}

The integer cuts are:

- $y_{b i t}^{I} \leq y_{b i}^{I-M P, r} \quad \forall b, i, t$

- $y_{j q s t}^{J} \leq y_{j q}^{J-M P, r} \quad \forall j, q, s, t$

- $\quad y_{k s t}^{K} \leq y_{k}^{K-M P, r} \quad \forall k, s, t$

- $\left\lfloor{\overline{n_{d g t}^{r e f}}}^{r}\right\rfloor \leq \sum_{a} n_{d g t a} \leq\left\lceil{\overline{n_{d g t}^{r e f}}}^{r}\right\rceil \quad \forall d, g, t$ 
Each magnitude with a line above (i.e. $\bar{y}_{b i}^{I-M P, r}, \overline{n_{d g t}^{r e f}}$, etc) refers to the value of this variable in the solution of model MP at iteration $r$.

The model SP yields an upper bound because only integer cuts have been added to the original problem P, which reduce the feasible region.

\subsection{Algorithmic Steps}

The detailed algorithm implemented according to Fig. 1 is as follows:

Step 1: Set $\mathrm{r}=0 ; \mathrm{UB}=\infty ; \mathrm{LB}=-\infty$; and fix the maximal tolerance allowed between bounds

Step 2: Set $r=r+1$ and $R=r$. Solve the aggregate model MP to obtain a configuration of processes. Set LB $=c(v a l u e$ of the objective function). Define:

$$
\begin{aligned}
& Z_{1}^{I, r}=\left\{b, i \mid \bar{y}_{b i}^{I-M P, r}=1\right\} \\
& Z_{0}^{I, r}=\left\{b, i \mid \bar{y}_{b i}^{I-M P, r}=0\right\} \\
& Z_{1}^{J, r}=\left\{j, q \mid \bar{y}_{j q}^{J-M P, r}=1\right\} \\
& Z_{0}^{J, r}=\left\{j, q \mid \bar{y}_{j q}^{J-M P, r}=0\right\} \\
& Z_{1}^{K, r}=\left\{k, q \mid \bar{y}_{k q}^{K-M P, r}=1\right\} \\
& Z_{0}^{K, r}=\left\{k, q \mid \bar{y}_{k q}^{K-M P, r}=0\right\}
\end{aligned}
$$

Step 3: Incorporate the information of the solution of model MP through Eqs. (87) - (90). Solve model SP to determine a plan of investments in different industries and the number of petrol stations required to meet the demand.

a- If model SP is infeasible, add Integer Cuts 1 to problem MP in order to avoid previous solution.

Go to Step 2

Integer Cuts 1: \{Eq. (79)\}

b- If model SP is feasible set $\mathrm{UB}=\mathrm{c}$ (value of the objective function). Check convergence.

If (UB-LB) / UB $\leq$ tolerance, then stop and the optimal solution is the one obtained in SP and the corresponding UB. Otherwise, continue with step 4: 
Step 4: Add the Integer Cuts 2 to model MP in order to increase the lower bound.

Go to Step 2.

Integer Cuts 2:

\{Eq. (79) to avoid previous solutions\}

\{Eq. (80) - (82) to preclude supersets\}

\{Eq. (83) - (85) to preclude subsets\}

\{Eq. (86) to guarantee demand satisfaction\}

End

\subsection{Results of the Decomposition Algorithm}

This algorithm is applied to the Detailed Model Example described in Section 5.2 and the results obtained are summarized in this section. All problems have been modeled with GAMS 23.8 and solved with solver CPLEX 12.4.0.0 on a processor Intel Core i7-2640M 2.8GHz and RAM of $8 \mathrm{~GB}$.

The results for the full space method are presented in Table 9 of the main work, and the results for the decomposition algorithm are presented in Table 1.

MP has 177,339 equations and 174,854 variables, 21,939 out of them are discrete.

The main goal of this algorithm is to obtain a solution for the Detailed Model Example with a gap less or equal than the full space one (Table 9), and to decrease this gap in a computational time lower than the computational time required for the full space method.

Table 1. Results for Bilevel Decomposition algorithm

\begin{tabular}{ccccc} 
& Cost & Time & $\begin{array}{c}\text { CPLEX } \\
\text { Gap } \\
\text { Iter-Model }\end{array}$ & $\begin{array}{c}\text { Algorithm } \\
{[\text { GM USD }]}\end{array}$ \\
\hline 1-MP & $162,862.6$ & 385.1 & 0 & 1.56 \\
1-SP & $165,954.5$ & $2,150.3$ & 0.500 & \\
2-MP & $163,750.5$ & $1,125.7$ & 0.051 & 1.06 \\
2-SP & $165,510.1$ & $1,244.0$ & 0.325 & \\
3-MP & $164,012.1$ & 910.2 & 0.033 & 0.86 \\
3-SP & $165,440.1$ & $1,501.7$ & 0.310 & \\
\hline TOTAL & $165,440.1$ & $7,317.0$ & & 0.86 \\
TIME & & & & \\
\hline
\end{tabular}


Table 1 and Figure 3 show that not only the gap is lower than the one obtained with the full space method (1\%), but also the computational time is lower (7,317 CPU seconds vs. 11,856.2 CPU seconds).

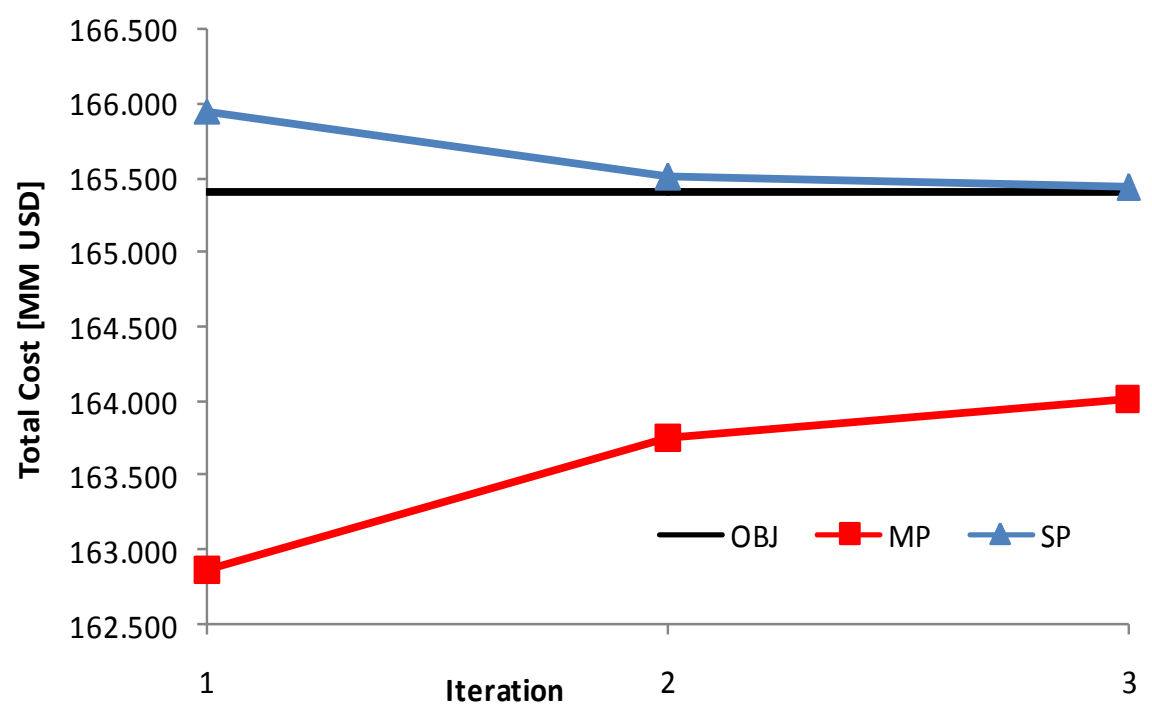

Figure 3. Results of Bilevel Decomposition algorithm

\section{References}

1. Dogan E., Grossmann I.E. A Decomposition Method for the Simultaneous Planning and Scheduling of Single Stage Continuous Multiproduct Plants. Ind. Eng. Chem. Res. 2006, 45, 299-315.

2. Iyer R., Grossmann I.E. A Bilevel Decomposition Algorithm for Long-Range Planning of Process Networks. Ind. Eng. Chem. Res.1998, 37, 474-481.

3. Terrazas-Moreno S., Grossmann I.E. A multiscale decomposition method for the optimal pla nning and scheduling of multi-site continuous multiproduct plants. Chemical Engineering Science 66 (2011) 4307-4318 


\section{Appendix A}

In the derivation of the higher level problem, the subscripts of size and year was eliminated from the binary variables. Then, Eqs. (16); (17); (28) and (29) are modified according to the following description.

$$
\sum_{q} \sum_{s} y_{j q s t}^{J} \leq N J_{j t}^{T O T} \quad \forall j, t
$$

The main idea is to eliminate the subscripts of size and time ( $s$ and $t$ ) and obtain a relaxation for Eq. (16). In the following line, we apply a summation over index $s$ and the whole equation is divided by card $(s)$.

$$
\sum_{q}\left(\sum_{s} y_{j q s t}^{J}\right) \leq N J_{j t}^{T O T} \quad \forall j, t \quad \Leftrightarrow \quad \sum_{q} y^{i n t}{ }_{j q t}^{J} \leq N J_{j t}^{T O T} \quad \forall j, t \quad \Leftrightarrow \quad \sum_{q} y^{i n t 2}{ }_{j q t}^{J} \leq \frac{N J_{j t}^{T O T}}{\operatorname{card}(s)} \quad \forall j, t
$$

with: $\quad 0 \leq y^{i n t}{ }_{j q t}^{J} \leq \operatorname{card}(s)$ and $0 \leq y^{i n t 2}{ }_{j q t}^{J} \leq 1 \quad$ where: $\quad y^{i n t 2}{ }_{j q t}^{J}=\frac{y^{i n t}{ }_{j q t}^{J}}{\operatorname{card}(s)}$

Then, over the summation of $t$ :

$$
\Leftrightarrow \quad \sum_{q} \sum_{t} y^{i n t 2}{ }_{j q t}^{J} \leq \sum_{t} \frac{N J_{j t}^{T O T}}{\operatorname{card}(s)} \quad \forall j \quad \Leftrightarrow \quad \sum_{q} y^{i n t 3}{ }_{j q}^{J} \leq \frac{\sum_{t} N J_{j t}^{T O T}}{\operatorname{card}(s)} \quad \forall j
$$

with: $\quad 0 \leq y^{i n t 3}{ }_{j q}^{J} \leq \operatorname{card}(t)$

Finally, if we divide all the equation by $\operatorname{card}(t)\left(y_{j q}^{J-M P}=y^{i n t 3}{ }_{j q}^{J} / \operatorname{card}(t)\right)$ Eq. (16) can be replaced by its relaxation in the formulation of the higher level, Eq. 64.

$$
\sum_{q} y_{j q}^{J-M P} \leq \frac{\sum_{t} N J_{j t}^{T O T}}{\operatorname{card}(s) \operatorname{card}(t)} \quad \forall j
$$

And the relaxation of Eq. (17) can be performed in a similar way:

$$
\sum_{j} y_{j q s t}^{J} \leq N J_{q s t} \quad \forall q, s, t
$$

The main idea is to eliminate the subscripts of size and time ( $s$ and $t$ ) and obtain a relaxation for Eq. (17). In the following line, we apply a summation over index $s$ and the whole equation is divided by card $(s)$.

$$
\sum_{j}\left(\sum_{s} y_{j q s t}^{J}\right) \leq \sum_{s} N J_{q s t} \quad \forall q, t \quad \Leftrightarrow \quad \sum_{j} y^{i n t}{ }_{j q t}^{J} \leq \sum_{s} N J_{q s t} \quad \forall q, t \quad \Leftrightarrow \quad \sum_{q} y^{i n t 2}{ }_{j q t}^{J} \leq \frac{\sum_{s} N J_{q s t}}{\operatorname{card}(s)} \quad \forall q, t
$$


Then, over the summation of $t$ :

$$
\Leftrightarrow \quad \sum_{q} \sum_{t} y^{i n t 2}{ }_{j q t}^{J} \leq \sum_{t} \frac{\sum_{s} N J_{q s t}}{\operatorname{card}(s)} \quad \forall q \quad \Leftrightarrow \quad \sum_{q} y^{i n t 3^{J}}{ }_{j q} \leq \frac{\sum \sum_{s} N J_{q s t}}{\operatorname{card}(s)} \quad \forall q
$$

Finally, if we divide all the equation by $\operatorname{card}(t)$ Eq. (17) can be replaced by its relaxation in the formulation of the higher level, Eq. 64.

$$
\sum_{j} y_{j q}^{J-M P} \leq \frac{\sum_{t s} \sum N J_{q s t}}{\operatorname{card}(s) \operatorname{card}(t)} \quad \forall q
$$

In a very similar way, Eqs. (28) and (29) can be converted into Eqs. (67) and (68). 